\title{
Acerca de la expresión de la condicionalidad y de la concesividad en judeoespañol moderno escrito
}

\author{
Sandra Schlumpf \\ Seminar für Iberoromanistik, Universität Basel
}

La condicionalidad y la concesividad constituyen dos categorías lingüísticas estrechamente relacionadas, que hasta el momento apenas se han estudiado en judeoespañol. A esta laguna desea contribuir el presente trabajo, cuyo objetivo principal es ofrecer una síntesis acerca de los mecanismos de expresión condicional y concesiva en textos sefardíes de los años 1880 a 1930. El estudio toma en consideración tanto aspectos sintáctico-formales como semántico-pragmáticos y contextuales. Aparte de las oraciones condicionales y concesivas prototípicas, asimismo se presentan dos categorías periféricas: las oraciones pseudocondicionales y las condicionales concesivas.

Para la historia del judeoespañol, las décadas señaladas se caracterizan por profundos procesos de elaboración lingüística con el fin de ampliar y modernizar la lengua. Dicha elaboración ante todo se nutrió de los contactos con el francés y el italiano y, aunque donde más se hace notar es en el léxico, también halla su reflejo en la sintaxis, así por ejemplo, en las construcciones condicionales y concesivas.

PALABRAS Clave: judeoespañol; condicionalidad; oraciones condicionales; concesividad; oraciones concesivas; conjunciones; sistema verbal; contacto lingüístico; elaboración lingüística.

ON THE EXPRESSION OF CONDITIONALITY AND CONCESSIVITY IN MODERN JUDEO-SPANISH.Conditionality and concessivity are two linguistic categories that are closely related. So far, they have hardly been studied in Judeo-Spanish. This article helps closing this research gap. As its main objective, the paper offers a synthesis of the linguistic mechanisms of conditional and concessive expression in Sephardic texts from 1880 to 1930. The considered linguistic mechanisms do not only include syntactic aspects but also semantic, pragmatic and contextual ones. Next to the prototypical conditional and concessive

\footnotetext{
"sandra.schlumpf@unibas.ch
} 
clauses, two further, peripheral categories will be presented: the pseudo-conditionals and the concessive conditionals.

For the history of Judeo-Spanish, the mentioned decades are characterized by processes of expanding and modernizing the language. This development is primarily influenced by the contact with French and Italian and can not only be observed in the lexicon but also in syntactic structures such as the conditional and concessive clauses.

KeYwords: Judeo-Spanish; Conditionality; Conditional Clauses; Concessivity; Concessive Clauses; Conjunctions; Verbal System; Language Contact; Language Modernization.

\section{INTRODUCCIÓN}

La condicionalidad y la concesividad constituyen dos áreas de investigación interrelacionadas en sincronía y diacronía debido a razones sintácticas, semánticas y pragmáticas. Uno de los rasgos distintivos tanto de las oraciones condicionales como de las concesivas es su complejidad en varios niveles del análisis, por lo que en la bibliografía se hallan múltiples afirmaciones como las siguientes: «las condicionales son, probablemente, la clase más compleja de expresión compuesta» (MonToLío 1999a: 3647); «en realidad, las concesivas presentan una estructura lógico-semántica considerablemente más compleja que las condicionales» (Rivas 1989: 238).

Por lo que concierne a la condicionalidad y la concesividad en judeoespañol, hasta ahora se constata una casi total falta de estudios, lo cual contrasta con la gran cantidad de trabajos dedicados a dichas clases oracionales en castellano y otras lenguas. Esta situación corresponde con la general escasez de estudios amplios sobre la sintaxis del judeoespañol, laguna a la que deseamos contribuir con nuestra investigación.

Nuestro objetivo primordial consiste en la descripción y el análisis de los mecanismos lingüísticos empleados para transmitir contenidos condicionales o concesivos en judeoespañol moderno escrito. Para ello nos basamos en un corpus de textos sefardíes de los años 1880 a 1930, que abarca alrededor de medio millón de palabras. Dada la ya señalada complejidad de la temática, tenemos en cuenta diferentes niveles del análisis: aspectos sintáctico-formales (p. ej. formas y esquemas verbales, los conectores y el orden de las dos cláusulas oracionales), aspectos lógico-semánticos (p. ej. cuestiones tipológicas e interferencias conceptuales con otras clases de ora- 
ciones) y aspectos discursivos y contextuales (p. ej. diferentes registros y tipos textuales, la autoría, las fechas y los lugares de publicación). Más allá de los objetivos indicados, el tema permite encontrar o comprobar características generales de la lengua sefardí, relacionadas, por ejemplo, con el funcionamiento de su sistema modo-temporal, sobre todo en el ámbito de las oraciones complejas, o con los procesos de ampliación, modernización y elaboración linguíísticas de los siglos XIX y XX.

Por lo que atañe a la estructura del presente artículo', para empezar hablaremos del judeoespañol moderno en el Imperio Otomano, prestando especial atención al contexto histórico-político y sociocultural del siglo XIX. Luego presentaremos el corpus de textos sefardíes que constituye la base documental del análisis y explicaremos la configuración de las oraciones analizadas. Después nos dedicaremos a las distintas clases oracionales: las condicionales, las concesivas y dos categorías periféricas: las pseudocondicionales (cuya semántica no es propiamente condicional) y las condicionales concesivas (un grupo intermedio situado en el límite entre la condicionalidad y la concesividad). En cada caso ofreceremos un acercamiento teórico y un resumen de la situación en los textos sefardíes, considerando aspectos tales como la distribución cuantitativa de los mecanismos lingüísticos empleados, la aparición de las oraciones según tipos textuales y ciertos factores contextuales. Cerraremos el artículo con unas conclusiones finales.

2. El JUdEOESPAÑOL (MODERNO): CONTEXTO HISTÓRICO-POLÍTICO Y SOCIOCULTURAL

Frente al castellano, con el que comparte sus raíces medievales, el judeoespañol se caracteriza por ser una lengua de diáspora. Se ha formado a partir de 1492, cuando todos los judíos no dispuestos a adoptar la religión católica fueron expulsados de Castilla y Aragón. Además del Occidente europeo y el Norte de África, la principal zona de asentamiento de los

${ }^{1}$ Se trata de una síntesis de los resultados principales de nuestra tesis doctoral, realizada en la Universidad de Basilea, Suiza, en el marco de la Hermann Paul School of Linguistics y defendida en 2014. Ante todo le damos las gracias por toda su ayuda a Beatrice Schmid (Universität Basel), directora de la tesis; además, le agradecemos a Aitor García Moreno (CSIC, Madrid) sus sugerencias para este artículo. 
judíos sefardíes ( $c f$. hebreo Sefarad 'Península Ibérica') fue el Imperio Otomano, donde sobre todo en ciudades como Salónica, Estambul o Esmirna fundaron comunidades importantes ${ }^{2}$. La organización interna del Imperio, caracterizado por su heterogeneidad étnico-religiosa, permitió que los judíos, a cambio de impuestos, mantuvieran no solo una organización autónoma de su comunidad y su propio sistema de enseñanza, sino también sus costumbres, su religión y su lengua. Otros hechos que influyeron en la evolución del judeoespañol en el Imperio Otomano son la falta de contacto con el castellano y la Península Ibérica desde el siglo XVII, la ausencia de una política lingüística y las influencias de las lenguas de contacto (el hebreo, lengua del culto judío; el turco, lengua del estado otomano; el italiano, lingua franca en el comercio mediterráneo; y, regionalmente, el griego, el búlgaro, el serbio, el rumano, etc.). A la época de formación de la variedad sefardí en los siglos XVI-XVII le siguió una primera época de plenitud en el siglo XVIII, que llevó a la consolidación de lo que hoy se conoce como judeoespañol clásico ${ }^{3}$.

El inicio del siglo XIX fue uno de los momentos más difíciles en la historia del Imperio Otomano ( $c f$. BARNAÏ 1992a: 142-151; FAROQHI 2003: 251-255; VeINSTEIn 1993: 364-366). Problemas económicos, políticos y militares, acompañados por una general falta de modernización, favorecieron un amplio descontento en la sociedad, revueltas locales y un creciente antisemitismo. El estado otomano intentó contrarrestar dichas dificultades aumentando los impuestos, promoviendo la modernización y secularización del Imperio mediante una serie de reformas conocidas como tanzimat (turco, 'regularización', 'organización', 'nuevo orden', $1839-1876)^{4}$ y abriendo sus puertas hacia las potencias occidentales cris-

${ }^{2}$ Como visión de conjunto sobre la diáspora sefardí recomendamos BenBassa y Rodrigue (2004). Más específicamente sobre la diáspora en el Imperio Otomano también pueden consultarse DíAz-Mas (2006: 68-85), HASSÁN (1995: 118-125), ROMERo (2008: 159-161) y Romero Castelló y Macías Kapón (1994: 48-55), entre otros.

3 Sobre la época de formación y la lengua sefardí en la época clásica pueden consultarse, entre otros, HASSÁN (1995: 125-126), MiNERVINI (2002; 2008), ROMERO (2008: 170-177) у SCHMID (2008: 64-67).

4 Informaciones sobre las reformas otomanas en el siglo XIX y, en general, sobre la época de modernización y secularización del estado se hallan en BENBASSA y RodRIGUE (2004: 173-184), FAROQHI (2003: 275-281), LEVY (1992: 98-104), VEINSTEIN (1993: 366367) y WEIKER (1992: 115-148). 
tianas. A pesar de sus esfuerzos, el gobierno otomano no consiguió restituir el poder central del estado ni debilitar los crecientes movimientos nacionalistas en varias zonas del Imperio, evolución que desembocó en la creación de nuevos estados nacionales (Grecia, Serbia, Macedonia, Bulgaria y Rumanía, etc.) y, finalmente, en la proclamación de la República de Turquía en 1923.

Los cambios mencionados también afectaron a los sefardíes residentes en el Imperio. En un contexto de general apertura del Imperio hacia Occidente y de creciente interés de Europa por los sucesos en el Imperio, las élites sefardíes buscaron el contacto con comunidades judías fuera del Imperio, quienes, a su vez, empezaron a interesarse por sus correligionarios otomanos. En consecuencia aumentó la influencia europea en el mundo sefardí oriental, en primer lugar a través de escuelas europeas que se establecieron en tierras otomanas ( $c f$. ROMERo 2008: 178-180). La institución más importante fue la Alliance Israélite Universelle, fundada en París en 1860 por un grupo de burgueses judíos liberales ${ }^{5}$. La Alianza abrió su primera escuela en el Imperio Otomano en 1862 en Tetuán, Marruecos (BENBASSA y RodRIGUe 2004: 201), y hasta 1940 se fundarían un total de 205 escuelas en quince países actuales (WEIKER 1992: 198-199). Las escuelas de la Alianza implantaron en tierras otomanas un modelo educativo propio de la Francia del siglo XIX -los planes de estudio se orientaban en los modelos vigentes en Francia y la lengua de enseñanza era el francés-, que conllevó la occidentalización y europeización -o mejor dicho, el afrancesamiento- de la sociedad judía.

El impacto que tuvo la red de escuelas de la Alianza en la vida de los judíos sefardíes otomanos fue profundo y se hizo notar en su vida social y cultural, en la economía, la política, la administración de las comunidades y el sistema educativo. La Alianza representaba el progreso y la enseñanza moderna de carácter laico, y la cultura y la lengua francesas se convirtieron en símbolos de la emancipación y modernidad.

5 Sobre las transformaciones en el ámbito educativo sefardí en el siglo XIX y especialmente sobre el rol de la Alliance Israélite Universelle, véanse BENBASSA y RODRIGUE (2004: 200-211), JE (s.v. Alliance Israélite Universelle), LEVY (1992: 112-115), RoDRIGUE (1990: 71-99) y WeIKER (1992: 193-214). Además de la Alianza, son de mencionar las escuelas italianas de la Società Dante Alighieri (cf. http://www.ladante.it) y las escuelas vienesas de la familia Camondo (cf. De Benmergur 2007). 
Por lo que atañe a la lengua sefardí, uno de los cambios más importantes fue la introducción de los llamados géneros adoptados ${ }^{6}$, géneros textuales sin tradición en la literatura judía precedente: la prensa, la narrativa, el teatro secular y la poesía de autor. Su producción y difusión conllevó un proceso de elaboración lingüística, que en primer lugar se nutrió de los contactos (nuevos o intensificados) con el francés y el italiano. Por consiguiente, las transformaciones e innovaciones lingüísticas que caracterizan este judeoespañol moderno no solo conllevaron la ampliación y modernización de la lengua, sino también su occidentalización y rerromanización ${ }^{7}$.

En cuanto a los diferentes niveles de la lengua, es en el vocabulario donde más se hizo notar la influencia gala -y en menor medida, la italiana-, en forma de préstamos léxicos con o sin adaptación fonética o morfológica ( $c f$. ScHMID 2008: 69-71). Asimismo se amplió la terminología específica ( $c f$. , p. ej., SÁNCHEZ 2012 y RIEDER-ZELENKo 2014) y se elaboraron nuevos mecanismos estilístico-discursivos ( $c f$. BÜRKI 2006: 62-74 y ScHMID 2008: 69). Por lo que respecta a la morfosintaxis, las innovaciones se observan, por ejemplo, en elementos lingüísticos con funciones primordialmente gramaticales, como las conjunciones o las locuciones, y en ciertos empleos de los tiempos y modos verbales.

En suma, el judeoespañol moderno -o neojudeoespañol- destaca como modelo de variedad lingüística de baja presión normativa (frente al castellano moderno, por ejemplo), que permite una mayor libertad de evolución y selección de formas, términos, esquemas gramaticales, etc., aunque dentro de tales vacilaciones y un cierto polimorfismo se muestran tendencias marcadas hacia la regularización y simplificación lingüísticas ( $c f$. García Moreno 2006: 35-36 y 49-50). Las diferencias frente al español normativo se deben a tres factores principales ( $c f$. SCHMID 2008: 60-61): retenciones de soluciones medievales; innovaciones propias, ma-

6 Sobre los nuevos géneros literarios que desde mediados del siglo XIX empezaron a cultivarse entre los judíos sefardíes de Oriente véanse, especialmente, DíAz-Mas (2000; 2006: 94-212) y ROMERO (1992: 177-312; 2008: 178-186).

7 Nótese que dicho proceso de ampliación y occidentalización -y sobre todo el afrancesamiento- no siempre se ha interpretado como promotor de la modernización y reavivación de la lengua, sino también como factor que aceleró su desintegración y declive (cf. HARRIS 1994: 205-208). 
yormente inherentes al castellano y elegidas en judeoespañol con el fin de regularizar y simplificar la lengua; y la influencia de las lenguas de contacto, en la época moderna sobre todo del francés y del italiano.

\section{El CoRpus de teXtos SEFARdíEs MemTet}

Para nuestro estudio sobre las oraciones condicionales y concesivas nos hemos basado en un corpus de textos sefardíes representativo del judeoespañol moderno escrito, que demuestra la gran difusión del neojudeoespañol y ofrece una rica fuente de materiales para estudios lingüísticos. Se trata del corpus llamado MemTet, que fue elaborado en los años 2003 a 2004 en la Universidad de Basilea en el marco del proyecto «Entre tradición y modernidad: El judeoespañol de Oriente entre 1880 y 1930» bajo la dirección de la profesora Beatrice $\mathrm{Schmid}^{8}$. Es un amplio conjunto de obras sefardíes con una extensión total de unas 522.000 palabras. Todos los textos fueron publicados, originalmente en aljamía hebraica, durante las décadas señaladas en las siguientes ciudades de la región mediterránea oriental: El Cairo, Esmirna, Estambul, Jerusalén, Ruse (Bulgaria), Salónica, Sarajevo, Sofía y Xanti (Grecia). El corpus incluye tanto producciones sefardíes originales como traducciones de otras lenguas y comprende diversos tipos textuales: textos literarios, periodísticos, humorísticos y administrativos, conferencias y discursos, así como una serie de textos sin afiliación a ninguno de los tipos mencionados, que por ello se reúnen bajo varia".

En suma, el corpus refleja la rica producción literaria en lengua judeoespañola desde 1880 hasta 1930, una época caracterizada por profundas trans-

${ }^{8}$ Una descripción del proyecto se halla en:

http://ladino.unibas.ch/proyectos/entre-tradicion-y-modernidad/; para más informaciones sobre el corpus MemTet, véase:

http://ladino.unibas.ch/proyectos/entre-tradicion-y-modernidad/el-corpus-memtet/.

9 Junto a los ejemplos sefardíes que se citan en este artículo indicamos las siglas convenidas para cada texto en el marco del proyecto; véase para ello el listado de textos disponible en:

http://ladino.unibas.ch/proyectos/entre-tradicion-y-modernidad/el-corpus-memtet/. Las letras minúsculas contenidas en cada sigla remiten, del siguiente modo, al género textual: $\mathrm{a}=$ textos administrativos, $\mathrm{c}=$ conferencias, $\mathrm{d}=$ discursos, $\mathrm{h}=$ textos humorísticos, $\mathrm{n}=$ narrativa, $\mathrm{p}=$ prensa, $\mathrm{t}=$ teatro, $\mathrm{v}=$ varia . 
formaciones políticas, sociales y culturales en el mundo sefardí oriental (vid. apdo. anterior). Por lo que respecta a la lengua, en esta media centuria el judeoespañol diversifica, consolida y pone en práctica los recursos léxicos y morfosintácticos adquiridos o desarrollados durante el proceso de elaboración lingüística iniciado a mediados del siglo XIX. Por consiguiente, a partir del corpus se pueden realizar estudios lingüísticos cuyos resultados permiten describir tendencias, formular hipótesis y sacar conclusiones bien fundamentadas y de validez general para la lengua sefardí en la época moderna.

\section{CONFIGURACIÓN DE LAS ORACIONES CONDICIONALES Y CONCESIVAS ANALIZADAS}

En total, hemos analizado 1811 oraciones condicionales y concesivas procedentes del corpus MemTet ${ }^{10}$. Los números de ocurrencias de las distintas clases oracionales son bastante desiguales, pero representativos para el empleo cuantitativo de cada categoría en la lengua ( $c f$. gráfico 1): una mayor frecuencia de las condicionales (1148 ocurrencias), seguidas por las concesivas (309 ocurrencias) y, finalmente, por las categorías intermedias y periféricas: las condicionales concesivas (192 ocurrencias) y las pseudocondicionales (162 ocurrencias).

Como muestra el gráfico, hemos establecido diferentes subcategorías que permiten un estudio más estructurado y detallado. En el caso de las oraciones condicionales (vid. apdo. 5.2), se pueden diferenciar, básicamente, las condicionales mayoritarias construidas con la conjunción si de una serie de estructuras menos habituales. Estas últimas incluyen tanto los conectores minoritarios como ciertos usos del imperativo y las construcciones condicionales con formas no personales del verbo.

Los cuatro tipos de oraciones pseudocondicionales representan un conjunto periférico (vid. apdo. 7). En su mayoría emplean el conector condicional prototípico si, pero guardan relaciones con otras categorías oracionales, por ejemplo con las comparativas o las adversativas.

${ }^{10}$ Nuestra tesis doctoral además incluye el estudio de 2489 oraciones adversativas halladas en el corpus MemTet. Constituyen el mecanismo lingüístico más habitual para expresar un contraste, de ahí sus relaciones con las concesivas. En esta contribución, sin embargo, nos limitamos a las dos categorías núcleo, esto es, las condicionales y las concesivas. 


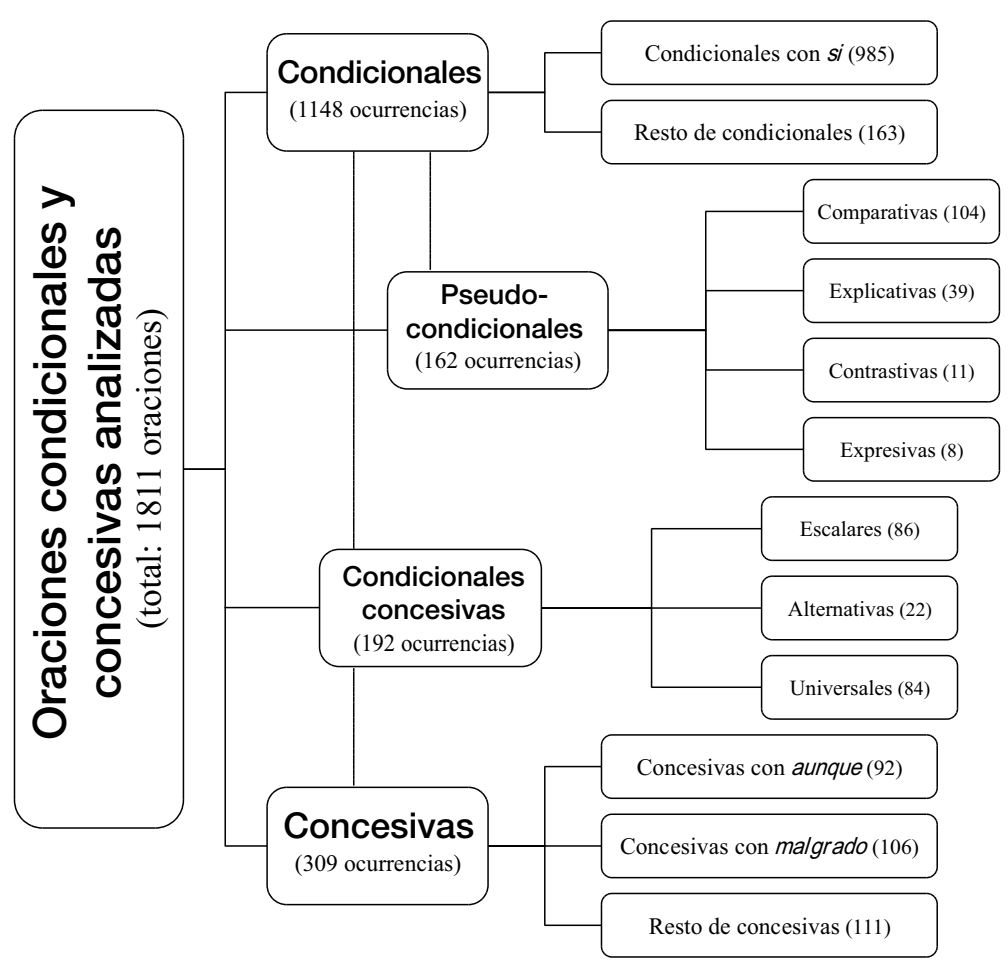

Gráfico 1. Síntesis de las oraciones condicionales y concesivas analizadas.

Siguen las construcciones condicionales concesivas, que actúan de puente entre las dos clases (vid. apdo. 8). Se subdividen en tres tipos -las concesivo-condicionales escalares, alternativas y universales-, que a su vez reflejan el continuum categorial que lleva desde la condicionalidad hacia la concesividad.

Llegados así al grupo de las oraciones concesivas (vid. apdo. 6.2), nos hallamos ante una subdivisión comparable a la de las condicionales: por un lado, mecanismos mayoritarios (en este caso, aunque y malgrado [que]), y por otro, estructuras minoritarias, incluidas las formas no personales del verbo que permiten manifestar concesividad. 


\section{Condicionalidad}

\subsection{Aspectos teóricos}

La condicionalidad puede manifestarse de maneras muy variadas en la lengua, tanto en lo que concierne a los rasgos formales y léxicos, como también con respecto a los distintos matices semánticos que se engloban bajo este concepto ( $c f$. NGLE 2010: 3565). Sin dudas, la estructura sintáctica prototípica para expresar una condición en español siempre ha sido la construcción bimembre cuyos dos sintagmas se enlazan mediante la conjunción si. Pero también una serie de locuciones puede transmitir un significado condicional, por ejemplo en caso de que o a condición de que, así como verbos que «permiten crear mundos alternativos al real» (NGLE 2010: 3566), especialmente el verbo suponer. Además, en ciertos contextos las formas no personales del verbo, sobre todo el gerundio, y en ocasiones estructuras sin verbo alguno pueden expresar condicionalidad. En todos los casos, la cláusula subordinada o prótasis expone una causa o condición, mientras que la cláusula principal o apódosis relata su efecto o consecuencia. Cuando hay un elemento lingüístico que une ambas partes de la oración, su función es marcar de forma explícita el vínculo que el hablante establece entre ellas.

Dicha relación condicional -y por ende, causal- entre la prótasis y la apódosis es una de las características definitorias de las oraciones condicionales: una oración con la estructura si $p, q$ solo puede definirse como construcción condicional en el caso de que el segmento si $p$ exprese una acción condicionante que influye directamente en el segmento $q$, cuya realización, a su vez, depende de lo expuesto en $p$. De hecho, no todas las construcciones con los rasgos formales descritos son verdaderos períodos condicionales. SöHRMAn (1991: 28), por ejemplo, emplea el término de implicación y distingue entre implicaciones verdaderas como en: «Pues bien: si las cosas se ponen muy mal, voy a la embajada, y asunto terminado»; e implicaciones pretendidas como en: «Si ellos tienen uno, nosotros tenemos dos». En el caso de las implicaciones verdaderas, la prótasis expresa una condición que «influye en la apódosis, que es la consecuencia posible extraída de la suposición establecida en la prótasis» (SöHRMAN 1991: 28-29). Por el contrario, en un período de implicación pretendida 
[...] la prótasis sólo parece condicionar la apódosis a causa del uso de la construcción condicional, pero desde un punto de vista semántico y lógico el contenido de la prótasis no llega a ser una condición motivada para traer la consecuencia presentada a la acción de la apódosis. (SöHRMAN 1991: 152).

Mientras que la implicación verdadera coincide con las nociones de la condicionalidad y causalidad, los períodos de implicación pretendida no conllevan la idea básica de causa-efecto; trataremos estos últimos en el apdo. 7 sobre las oraciones pseudocondicionales. Resumiendo, solo se pueden considerar oraciones condicionales las construcciones compuestas por prótasis y apódosis que expresan una relación causal-condicional o de implicación verdadera (si $p$, [entonces] $q)^{11}$.

Por lo que respecta a la clasificación de las oraciones condicionales, la diversidad de propuestas teóricas es muy amplia. La mayoría de las propuestas pueden asignarse a dos grupos: las clasificaciones bipartitas y las clasificaciones tripartitas ${ }^{12}$. Por motivos prácticos y teóricos nosotros preferimos una clasificación tripartita y hemos definido los siguientes tres tipos, basándonos especialmente en SöHrman (1991: 41-49):

Primero, las oraciones condicionales reales, que expresan hechos conocidos por el hablante y calificados como realidades. En estos casos el

11 Los únicos casos que difieren ligeramente del modelo esbozado son las llamadas oraciones condicionales de la enunciación. Conforme a la NGLE (2010: 3551), se oponen a las condicionales del enunciado -que corresponden con las condicionales prototípicasy «se caracterizan por no establecer una relación causal entre prótasis y apódosis, sino entre la prótasis y cierta información obtenida de la apódosis a través de un verbo de lengua tácito o un razonamiento discursivo». Uno de los ejemplos citados por la NGLE (2010: 3552) es: «Si no estoy equivocado, el tren llegará a las diez en punto». En los textos sefardíes, hemos encontrado 45 oraciones condicionales de la enunciación, las cuales no comentaremos en este artículo. Un ejemplo sería: «Antes de empezar mi discorso, que me sea permetido de haćer una observación que se impone, de formular una reśerva, una excuśa enfín, si esta última expresión vos parecerá más justa». (MUJc,1)

12 Como representantes de clasificaciones dicotómicas se pueden citar: Alarcos Llorach (2002: 471-475), Contreras (1963: 44), el Esbozo (1973: 554-557), GiLi Gaya (1985: 319), Marcos Marín (1972: 256), Santana Marrero (2003: 40-43), Schneider (1995: 36), Seco (1988: 245-246) y Veiga y Mosteiro Louzao (2006: 152 y ss.). Para clasificaciones tricotómicas, véanse: DLM (s.v. Oración condicional), HerRERo RuIZ DE Loizaga (2005: 390-404), Montolío (1999a), Narbona Jiménez (1990: 87-88), Penny (2006: 278-284), Porcar Miralles (1993: 56), Rojo y Montero Cartelle (1983: 24), SERRANo (1994: 117 y ss.) y SöHrman (1991: 41 y ss.). 
locutor tiene la certeza sobre la veracidad de los hechos en el mundo real y sabe que las acciones descritas se han realizado, se realizan o se van a realizar. Desde el punto de vista del hablante, no se trata solo de hechos posibles, sino de hechos considerados como verdaderos. Ilustrémoslo con un ejemplo en judeoespañol:

(1) Bačhlén - Yo ya conozco a mi marido, si topa con quen ocuparse de la cencia es capace de olvidarse de su mujer. (FABt,358b)

Segundo, las oraciones condicionales hipotéticas, que expresan algo desconocido. El hablante no sabe si las acciones expresadas se han realizado, se realizan o se van a realizar, por lo que la situación queda abierta. Diferenciamos claramente entre condición -característica de cualquier oración condicional- e hipótesis; un «enunciado es condicional e hipotético sólo en el caso de que la hipótesis no se haya resuelto» (PorCAR Miralles 1993: 21) $)^{14}$.

(2) Si me dećís más una sola palabra, iyo llamo! (FABt,375a)

Tercero, las oraciones condicionales irreales. Designan acciones no realizadas en el pasado o acciones calificadas como no realizables en el presente o en el futuro, y el locutor tiene la certeza sobre la irrealidad de realización de los hechos descritos.

(3) Confesaremos que si nuestros oj́os non lo vían non lo creíamos. (EPp83,215b)

Como muestra el gráfico 2, las nociones de realidad e irrealidad constituyen los dos polos extremos de un continuum de posibles matices condicionales, representando tipos condicionales bien definidos y delimitados. En cambio, la noción de hipótesis abarca toda una gama de

13 Todas las cursivas y las mayúsculas en las citas son nuestras. Además, ponemos los signos de exclamación e interrogación según las normas del español actual y explicamos las palabras de difícil comprensión, basándonos en NehamaDict, BunisLex, SteuerwaldWb y NRedhouse.

${ }_{14}$ Muchos autores establecen una diferencia más o menos clara entre condición e hipótesis, pero mientras que algunos constatan que el concepto de condición es más amplio que el de hipótesis -tal como lo entendemos también nosotros-, otros sostienen lo contrario. Véanse, por ejemplo, Polo (1971: 90), Porcar Miralles (1993: 16-21), Montolío (1999a: 3647-3648) y Rodríguez Rosique (2008: 81-83), por un lado, y Contreras (1963), Narbona Jiménez (1990) y DeZa Enríquez (1993), por otro. 
condiciones dudosas - por tanto hipotéticas-, que comprenden los diferentes grados de probabilidad de realización. Por eso no es de extrañar que el grupo de las condicionales hipotéticas sea el más numeroso y heterogéneo.

\begin{tabular}{|c|c|c|}
\hline REALIDAD & HIPÓTESIS & IRREALIDAD \\
\hline $\begin{array}{l}\text { Condiciones } \\
\text { reales }\end{array}$ & $\begin{array}{l}\text { Condiciones hipotéticas } \\
\text { (probables, posibles, improbables, etc. }\end{array}$ & $\begin{array}{l}\text { Condiciones } \\
\text { irreales }\end{array}$ \\
\hline $\begin{aligned} & \text { Certeza } \\
+ & \text { afirmación }\end{aligned}$ & $\begin{array}{l}\text { Falta de certeza } \\
\text { + duda }\end{array}$ & $\begin{aligned} & \text { Certeza } \\
+ & \text { negación }\end{aligned}$ \\
\hline
\end{tabular}

Gráfico 2. Tipología esquemática de los tres tipos de oraciones condicionales.

\subsection{Las oraciones condicionales en judeoespañol moderno}

\subsubsection{Distribución cuantitativa de los conectores condicionales}

Igual que el español y otras lenguas románicas, el judeoespañol ofrece una distribución cuantitativa muy marcada de sus conectores condicionales (vid. gráfico 3): la gran mayoría de las oraciones se construye con la conjunción si $(85,80 \%)$, el único marcador condicional totalmente dominante. La misma conjunción se emplea en gran parte de las oraciones pseudocondicionales (vid. apdo. 7), además de que forma parte de conectores compuestos, como si en cavśo, si como, como si o si anque. Por consiguiente, si no solo resalta como conjunción más frecuente, sino también como la más plurifuncional, puesto que puede adquirir distintos matices semánticos y pragmático-discursivos.

Los conectores condicionales minoritarios que se hallan en MemTet no alcanzan ni un $12 \%$ de las condicionales analizadas. Entre ellos, tan solo las locuciones con $c a(v)$ śo tienen cierto peso, puesto que se emplean en un 8,44\% de los casos; aparecen construcciones como en (el) ca(v)śo que I ande I onde + sintagma verbal, si en cavśo, en ca(v)śo de + sustantivo o en (el) $c a(v)$ śo + adjetivo ( $c f$. ejs. 4-6). Estas fórmulas, que señalan un caso específico, y las que aluden a una condición concreta -que sin 


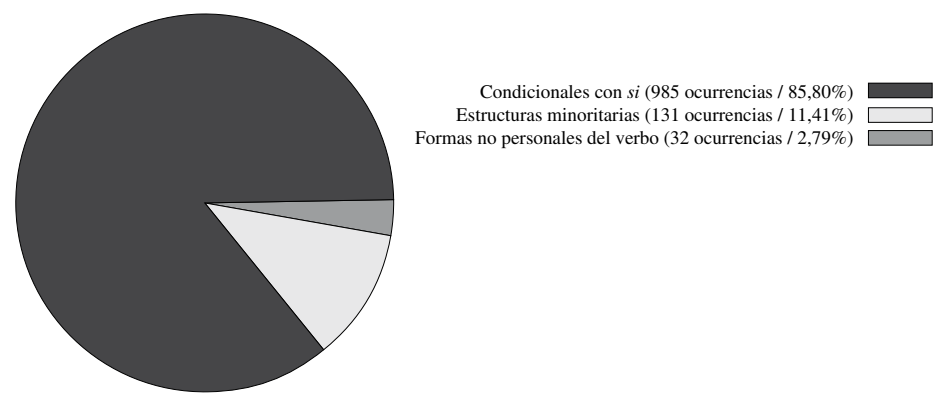

Gráfico 3. Distribución cuantitativa de los mecanismos condicionales.

embargo solo constituyen un 1,74\%- (p. ej. a [la] / soto la condición que + verbo conjugado o a [la] condición de + infinitivo; $c f$. ejs. 7-9) enfatizan el contenido condicional de manera mucho más explícita y concreta que la simple conjunción si. Sus usos además están ligados a ciertos tipos y registros textuales (vid. apdo. 5.2.3).

(4) En el cavśo ande la haćinura ['enfermedad'] de un maestro se prolonga más de 60 días, él será remplazado proviśoriamente, y el maestro hacćino ['enfermo'] non recibirá que la metad de su meśada. (ECa,10)

(5) Si en cavśo el siñor preśidente mancaría en horas de seduta ['reunión'], el viĉe preśidente terná el dirito de haćer las foncciones del preśidente. (HUMa,21)

(6) En caśo de igualidad de yoćes se tirará a la suerte. (EOa,11)

(7) La Alianza Yisraelita prometió de dar 45,000 francos para la construcción de un Talmud Torá ['escuela religiosa'] en Iźmir, a condición que la comunitá yisraelita de esta civdad aparte 20,000 francos para el miśmo escopo. (AVp2,4b)

(8) "Después de haber constatado los reśultados del voto, el Preśidente declara que el Congreso admite la independencïa de la Serḅía, ma soto la condición que la liḅertad reliǵiośa será reconocida en el Principato. [...]" (BERc,23)

(9) Esto quere dećir en otros términos que la Serbía será independente $a$ la condición de acordar a todos sus moradores la liḅertad reliǵiośa, y que sin liḅertad reliǵiośa non habrá Serḅía independente. (BERc,23)

El resto de los conectores condicionales analizados constituyen mecanismos muy poco habituales ( $c f$. ejs. 10-14): en tal que + subjuntivo, con 
la ayuda de + proyección al futuro, la conjunción principalmente temporal cuando (que prueba la estrecha relación entre la condicionalidad y la temporalidad) y algunas estructuras exceptivas (p. ej. a menos que + subjuntivo o construcciones con salvo).

(10) La madre era un poco flaca y haćina ['enferma']. Aun con todo ella dijo que se sacrificaría por yir a laźdrar ['trabajar'] en algún lugar en tal que su hija non saliera de caśa. Rośa no permitió esto. (PESn,4)

(11) -En estando solo, yo no puedo hacer nada, mientres que con la ayuda de cinco o seš hombres de valor yo me cargo de ganar en un año almenos un milión. (JJn6,9)

(12) Cuando algún maestro debe aỵsentarse por alguna raźón pośible, él debe aviśar imediatamente la dirección que apreciará si el motivo envocado es seriośo o non. $(\mathrm{ECa}, 10)$

(13) Aharón - Y después de estar algunas semanas, tú tornarás ande Ester, a menos que no te plaźga quedarte por entero con mí. Tu patrona ya está de acodro. (GUEt9,15b)

(14) Ellos no puedrán ser destituidos, salvo en caśo que cometerían una transgresión a la reliĝión o a la niźamname ['ley', 'reglamento']. $(\mathrm{EOa}, 12)$

Tampoco alcanzan cifras notables los imperativos con función condicional ( $c f$. ej. 15) ni los usos condicionales de las formas no personales del verbo (ejs. 16-18). En estos últimos el significado condicional normalmente se ve reforzado mediante otro elemento lingüístico, por ejemplo, en el caso del gerundio, el uso de los llamados verbos creadores de mundo (p. ej. imaǵinarse, creer, admitir, considerar y saber). Parece que en el corpus estudiado los empleos condicionales del infinitivo son algo más habituales que los del gerundio, pero en general tienen poca importancia y constituyen menos del $3 \%$ de las condicionales analizadas.

(15) Cuando vuestras mujeres vos haćen el preśente de un hijo o una hija (en este perat ['caso particular'] la cośa es indiferente) tomad una buena cuna, arodeada de colchonados de algodón, echad en riba la criatura dos o tres colchas de fanela ['franela'] que son más livianas y callentan mijor y meted a los pies, uno de cada parte, dos ladríos callentes amatados en la agua yelada y embrujados en un pedazo de fanela $y$ de esta manera la criatura estará mucho más caliente que en la cama de la madre. (EPp83,210b-211a) 
(16) Estate seguro, Chao, que en haćiendo como mí tú ganarás bastante y en pocos años ternás bastante por tornarte alegremente a Pequino ['Pekín']. (NCn,3b)

(17) Sabiendo que ereš venturośa yo hubiere podido adorarvos de lejos, sin dećirvos una palabra, sin echarvos una ojada que pudiese turbar vuestro repośo, ¡peró yo entendí que vós sufríš! (FABt,374c)

(18) Alberto.- [...] ¿Y agora qué? ¿Cree que con tomar un escribano de dos parás ['dinero'] le va caminar el hecho adelantre? (TSt2,116)

\subsubsection{Variación tipológica en las condicionales con $s i$}

Dada la distribución cuantitativa tan clara entre los mecanismos de expresión condicional, no sorprende que las condicionales con si demuestran la mayor diversificación en tipos y subtipos, con rasgos formales y semánticos propios. Dicho de forma resumida, la conjunción si se puede emplear siempre, en cualquier tipo textual y en todos los contextos semánticos, sintácticos y discursivos.

Por lo que concierne a los diferentes tipos condicionales, las reales (146 ocurrencias) son las que menos variación formal ofrecen, pero que por el contrario destacan por su diversidad semántica, que demuestra distintos puntos de contacto entre la condicionalidad y otras nociones. Básicamente, se pueden distinguir tres grupos de condicionales reales: las reales causales, cuya semántica las acerca a las oraciones causales (ej. 19); las acciones repetidas en el pasado, que manifiestan una temporalidad concreta en el pasado (ej. 20); y los juicios generales, que expresan atemporalidad o una temporalidad inespecífica, desligada de un momento temporal concreto (ej. 21). El papel primordial de la semántica en la subclasificación de las condicionales reales se ve respaldada por el uso de ciertas formas verbales, especialmente el presente (en las reales causales y los juicios generales) y el imperfecto (en las acciones repetidas en el pasado) de indicativo.

(19) Porque yo respecto siempre el refrán que diće: «Lo que no queres para ti no queras para tu compañero», y si como no quero que me hagan a mí limośna no hago ni yo a los otros... (YERp5,37b) 
(20) Si era invierno y que el siñor ḥajam ['sabio', 'maestro', 'rabino'] se hielaba, él metía las manos en la lumbre y se las caentaba. Si era enverano y que se cansaba, él se echaba para atrás y se durmía. (SUVv,5-6)

(21) El amigo que non sierve y el cuchío que non corta, si se piedre poco importa. (PURv,12)

Las condicionales hipotéticas (538 ocurrencias) constituyen el grupo más numeroso. Representan lo que se podría describir como "condicionales prototípicas" porque no solo postulan una condición, sino que formulan una hipótesis, es decir, el hablante manifiesta sus dudas con respecto a la realización de lo expresado. Puesto que las condicionales hipotéticas reúnen todo un continuum de hipótesis más o menos probables, no sorprende que ofrecen la mayor diversidad de esquemas verbales, según lo ejemplifican las siguientes citas:

(22) Si no me la dan me peleo. (SUVv,7)

(23) Después de haber meldado este chico estudio, nośotros vos demandaremos cuálo vos place mijor: si la mayoridad prefera el francés nośotros revendremos al francés, si queréš que continuemos en español nosótros mos conformaremos a vuestro gusto. (ESPc,1)

(24) Si vós daréš de vuestro tiempo, de vuestra moneda, de vuestra influenza en favor de estos mancebicos pobres estaréš bien seguros de hacer complido a uno de los doveres el más importante, no vos canséš, no vos espantéš de algún tropiezo que como luvia liviana viene y pasa. $(\mathrm{EPd} 84,612 \mathrm{~b})$

(25) Si le venían a mancar las fuerzas, él estaba piedrido. (NCn,26a)

(26) ¿Tú mismo qué dirías, si muestra querida muchacha caíba en el perícolo? (MARn,11)

Por el contrario, solo dos grupos de condicionales hipotéticas se distinguen del resto por los contenidos transmitidos, dos conjuntos relativamente pequeños en relación con el total de las oraciones hipotéticas: los consejos y mandatos (ej. 27), por un lado, y las normas (ej. 28), por otro.

(27) La ĝimnastica. Si queréš vivir munchos años haćed un poco de ex́ercicios corporales (ĝimnastica). (YERp5,38a) 
(28) [...] si alguno de muestros sorveliantes se topare con alguna mancanza o con un chico robo non solo que non será reconocido como soĉ, ma también recibirá un castigo según su mancanza. (HUMa,23)

Los consejos y mandatos sobre todo se caracterizan por la función apelativa de la apódosis, función comunicativa que asimismo se refleja a través de las formas verbales empleadas (imperativo o presente de subjuntivo). Además aparecen con predilección en situaciones dialogales -de ahí la alta presencia de ejemplos teatrales y narrativos- o en artículos periodísticos con una intención didáctica o apelativa. Las normas, por su parte, casi con exclusividad aparecen en textos administrativos y formulan reglas a seguir en el caso de que se produzca tal o cual situación.

Las condicionales irreales (175 ocurrencias) sobre todo son interesantes por los usos modo-temporales: el amplio uso del condicional, sobre todo en las apódosis, y el empleo predominante de dos de los esquemas más caracterizadores del (neo-)judeoespañol: $s i+$ imperfecto de indicativo + condicional y $s i+$ imperfecto de indicativo + imperfecto de indicativo. Volveremos sobre estos dos esquemas en el apdo. 5.2.4.

(29) Si él hubiera tomado mi consejo no sería tan deśventurado. (ANGt,50)

(30) ¡J́im J́ackson habría podido haćerse ladrón, si no se hubiere hecho poliz amator! (JJn6,9)

(31) -Si yo tenía unas manos como estas, repetaba él con entuśiasmo, yo sería milionario... (JJn6,9)

(32) Si. Bonefuá - [...] Si estabaš en otro país ya podiba ser, ma en esta civdad es cośa imposible. (HACt,15)

También se han analizado algunas oraciones condicionales con si que presentan esquemas verbales incompletos, es decir, que no presentan verbos en ambas cláusulas, sea porque al menos uno de los sintagmas carece de formas verbales, sea porque un sintagma falta por completo (81 ocurrencias). Su análisis ha demostrado que la parte suprimida (solo una forma verbal o toda una cláusula), o bien está presente en una oración anterior o posterior -y por tanto es fácilmente restituible- (ej. 33), o bien es sustituida por otro recurso lingüístico: signos de puntuación, mecanismos gramaticales, partículas léxicas, etc. (ejs. 34 y 35). Por lo demás, las condicionales con esquema verbal incompleto sobre todo se caracterizan por su aparición predilecta en registros y tipos textuales más informales. 
(33) Argán - Ella lo va haćer. Si no [lo va haćer], la vo meter en una iglesia. $(\mathrm{HACt}, 10)$

(34) ¡Oh! ¡Si me hubiere dicho una sola palabra, si me hubiere solamente espandido la mano! (FABt,373c)

(35) $\mathrm{H}-[\ldots]$ Y vośotros hijicos míos, que vos bendijo el Dio, si quieréš ser de verdad niños buenos y cumplidos, $n a$ ['he aquí'] lo que vaš a haćer. (MAZt,52a)

\subsubsection{Aparición de las condicionales según tipos textuales}

Por lo que atañe a la distribución de las condicionales según los diferentes tipos textuales, como observación general se puede retener que la conjunción universal si se emplea en todos los tipos de textos. Las desviaciones frente a los porcentajes relativos a la composición según tipos del corpus MemTet son más bien ligeras. Si nos fijamos en los porcentajes calculados para los distintos tipos condicionales, reconocemos las siguientes preferencias: las condicionales reales aparecen con más frecuencia que los demás tipos en la narrativa; en las hipotéticas destacan los textos administrativos (recuérdense las normas); y tanto en las hipotéticas como en las irreales y sobre todo en las condicionales con esquema verbal incompleto alcanza porcentajes altos el género teatral. Si tomamos en consideración las condicionales con si en su conjunto, solo exceden los porcentajes relativos a MemTet en el caso del teatro y de los textos administrativos. Las obras teatrales se componen de intervenciones más o menos cortas de los distintos personajes en estilo directo y el lenguaje utilizado se caracteriza por su registro más bien informal y familiar, que en muchas ocasiones intenta reflejar el uso oral de la lengua. Probablemente la alta frecuencia de las condicionales en los textos teatrales es un indicio de su gran difusión en la lengua hablada, situación opuesta a la de las concesivas.

Las locuciones condicionales con los elementos léxicos $c a(v)$ śo y condición ofrecen distribuciones cuantitativas muy distintas a la de la conjunción si: presentan cifras de ocurrencias mucho más limitadas, pero muestran preferencias más marcadas por aparecer en ciertos tipos textuales. Por lo que concierne a las construcciones con $c a(v)$ śo (96 ocurren- 
cias), sobresale la predominancia de los textos administrativos, de los que procede más de un $50 \%$ de los ejemplos. Sin dudas, el término $c a(v)$ śo se relaciona con el lenguaje jurídico por hacer alusión a los casos legales; probablemente estas locuciones condicionales no están gramaticalizadas del todo. Otro cuarto de las ocurrencias con $c a(v)$ śo procede de textos periodísticos, mientras que apenas aparecen en los géneros literarios. Tanto en el teatro como en la narrativa el conector condicional más habitual, no solo cuantitativa sino también porcentualmente, es si. En cuanto a los rasgos formales de las construcciones con $c a(v)$ śo, 43 de las 96 ocurrencias introducen sintagmas verbales, preferentemente con el verbo en indicativo, mientras que en los casos restantes, o bien se combinan con sustantivos o adjetivos, o bien constituyen sintagmas independientes (en este / tal l este último ca[v]śso).

También las locuciones con el elemento léxico condición (20 ocurrencias) constituyen conectores condicionales más marcados y explícitos que la conjunción $s i$, de ahí que no sorprenda su aparición predilecta en tipos textuales formales: en la prensa (un $40 \%$ de los casos, frente al $29 \%$ de textos periodísticos en MemTet), en conferencias (un 20\% frente al $5 \%$ en MemTet) y en discursos (un 15\% frente al 6\% en MemTet). Los últimos dos tipos están prácticamente ausentes entre los ejemplos con $c a(v)$ śo y tampoco son frecuentes en las condicionales con si. Por el contrario, ningún ejemplo con condición se halla en los textos administrativos, los cuales se caracterizan por un uso exclusivo de si y de las construcciones con $c a(v)$ śo. Otro rasgo que subraya el carácter formal de las fórmulas con condición es su preferencia por introducir cláusulas con verbos en subjuntivo.

\subsubsection{Variación sintáctica}

Cuando se intenta resumir las características sintácticas de las oraciones condicionales en judeoespañol moderno ${ }^{15}$, lo primero que salta a la vista es la gran variedad de esquemas verbales empleados. La libertad combinatoria modo-temporal entre prótasis y apódosis parece ilimitada,

15 Para un resumen de las tendencias modo-temporales más destacadas de las oraciones condicionales con si en el corpus MemTet, puede consultarse SCHLUMPF (2012a). 
hecho favorecido sin duda por la situación de baja presión normativa que caracteriza la historia de la variedad sefardí y que contrasta con la de lenguas fijadas por normas académicas. No obstante, la mayoría de los esquemas verbales constituyen casos poco frecuentes o incluso ocasionales, mientras que solo unos pocos alcanzan números de ocurrencias considerables, ante todo, $s i+$ presente de indicativo + presente de indicativo.

La más evidente tendencia sintáctica del judeoespañol en el campo de las condicionales -y al mismo tiempo la mayor diferencia frente al castellano- es la predilección por formas verbales del indicativo en casi todos los tipos analizados y en ambos sintagmas oracionales. Las únicas excepciones son las siguientes: por un lado, el predominio de formas condicionales en las cláusulas principales de las condicionales irreales (vid. ejs. 29-31 supra); y por otro, el empleo frecuente del subjuntivo en las condicionales introducidas por a (la) condición que (vid. ej. 7), en las ocurrencias aisladas de las locuciones en tal que y a menos que (vid. ejs. 10 y 13), así como en las pseudocondicionales comparativas (vid. apdo. 7.1 infra).

Por lo que atañe a las combinaciones verbales, además del esquema simétrico con formas del presente de indicativo resultan especialmente relevantes los esquemas $s i+$ imperfecto de indicativo + imperfecto de indicativo y $s i+$ imperfecto de indicativo + condicional para expresar condiciones hipotéticas e irreales (vid. ejs. 25-26 y 31-32 supra). Mientras que el primero de ellos es el esquema condicional más comentado en la bibliografía disponible sobre el judeoespañol ( $c f$. ., p. ej., BERENguer Amador 2002: 316-317; García Moreno 2004: 332; Montoliu y VAn Der Auwera 2004: 461; Varol 2004: 220), los datos obtenidos de MemTet prueban la mayor frecuencia del segundo en los textos modernos. Los dos esquemas expresan las relaciones modo-temporales del esquema español $s i+$ imperfecto de subjuntivo + condicional, que apenas se halla en el corpus, otra diferencia destacada entre el castellano y la lengua sefardí.

Ambas formas verbales utilizadas en los últimos esquemas judeoespañoles citados constituyen usos innovadores: el imperfecto de indicativo (en función del imperfecto de subjuntivo del español estándar) refleja -sin dudas ya en judeoespañol clásico- una simplificación modal, puesto que ya no es el modo, sino únicamente el tiempo pasado 
para referir acciones presentes el que sirve para expresar los matices de hipótesis e irrealidad, elección paralela a la que se dio, por ejemplo, en francés. Por otra parte, la notable difusión del condicional, sobre todo para manifestar irrealidad, ha de interpretarse como innovación de la época moderna, puesto que no está documentada en judeoespañol clásico. Probablemente su divulgación y consolidación fueron provocadas y fomentadas por el contacto intenso con la lengua francesa desde mediados del siglo XIX, cuyo esquema estándar para expresar condicionales hipotéticas e irreales de presente es, precisamente, $s i+$ imperfecto de indicativo + condicional.

Otro de los esquemas caracterizadores de las oraciones condicionales en judeoespañol es el que lleva formas del futuro de indicativo en las prótasis que hacen referencia a dicho plano temporal (vid. ej. 24 supra). En este caso se trata de la retención de un uso conocido también en castellano medieval, que en español ha ido disminuyendo hasta desaparecer casi por completo en el siglo XVI y que actualmente está tachado de incorrecto por la norma académica (NGLE 2010: 3571 y 3578). Su conservación en la lengua sefardí corresponde con la tendencia general hacia soluciones linguiísticas claras e inequívocas, aparte de que existe la posibilidad de que fuera apoyada por esquemas equivalentes en italiano contemporáneo.

También el empleo ocasional del futuro de subjuntivo en las condicionales judeoespañolas es un fenómeno conservador. Varios investigadores comentan su aparición muy rara en judeoespañol (BERENGUER AMADOR 2012: 58; Hetzer 2001: 46; SubaK 1905: 329; VAlentín DEL Barrio 2006: 2592) o incluso sostienen que ha desaparecido por completo (SALA 1983: 76). Nuestros datos confirman el empleo poco común de dicha forma verbal: su difusión es muy baja y se limita a las condicionales introducidas por si y en ca(v)śo que, y casi solo aparece en textos muy específicos, a saber, en documentos administrativos (vid. ej. 28 supra). Este tipo textual no solo en judeoespañol se caracteriza por emplear un lenguaje formal, más conservador y propicio a usar construcciones formularias fijas; también en español se observa ya en la época medieval una «especialización de Si tuvieres en las prótasis de las condicionales del lenguaje jurídico castellano para expresar cierta noción de contingencia» (MORAL DEL 
Hoyo 2012: 216) ${ }^{16}$. No todas las ocurrencias del futuro de subjuntivo en los textos sefardíes reflejan su función modo-temporal típica, a saber, la referencia hipotética al futuro; a veces desempeña las funciones propias del imperfecto o, en el caso de la forma compuesta, del pluscuamperfecto de subjuntivo español, hecho producido tal vez por una confusión fonética entre las formas en $-r e$ y en $-r a$ ( $c f$. ejs. 30 y 34). Por todo lo dicho, interpretamos los usos del futuro de subjuntivo en los textos estudiados como la retención de una forma verbal poco usada y consolidada, relegada casi únicamente al lenguaje jurídico.

Como última particularidad relacionada con los usos verbales en las condicionales analizadas es de señalar el empleo frecuente de esquemas verbales simétricos, término empleado por la NGLE (2010: 3577) para designar esquemas verbales que usan la misma forma verbal en ambos sintagmas de la oración. En el caso de las condicionales con si constituyen casi un 50\% de los casos (vid. ejs. 19-22, 24-25 y 32). Esta preferencia del judeoespañol por el empleo de la misma forma verbal en ambas cláusulas oracionales es -adicionalmente a la difusión del imperfecto de indicativo en vez del subjuntivo para expresar hechos no reales y la conservación del futuro de indicativo en las prótasis referentes al futuro- otra manifestación de su predilección por soluciones lingüísticas más sencillas, permitida de nuevo por la ausencia de una presión normativa. De hecho, el uso de esquemas simétricos en las oraciones compuestas se observa también en otras lenguas, especialmente en registros populares y en el lenguaje hablado, en los que abundan rasgos subestándares no aceptados por las respectivas normas académicas.

Quedan por resumir las tendencias en el orden de las dos cláusulas oracionales. La mayor parte de las oraciones condicionales muestra el orden canónico preferido también en español, esto es, prótasis antepuesta y apódosis pospuesta. Se observa, por ejemplo, en la mayoría de las condicionales introducidas por si o por las locuciones con $c a(v) s o$, así como en las condicionales que emplean formas del gerundio. Por el contrario, los ejemplos con condición y las condicionales exceptivas prefieren el orden opuesto, es decir, apódosis antepuesta y prótasis pospuesta (vid. ejs. 7-9 y 13-14 supra). Como se ha comentado, las

16 Sobre el futuro de subjuntivo en español pueden consultarse Camús Bergareche (1990), Eberenz (1990), Luquet (1988) y Moral del Hoyo (2012), entre otros. 
locuciones con condición resaltan por marcar de modo más explícito el contenido condicional de los enunciados, rasgo que tal vez apoye el orden no prototípico de tales oraciones; y las condicionales exceptivas destacan, como dice su nombre, por señalar una excepción, de ahí que el orden invertido al canónico sirva para enfatizar aún más el contenido de la cláusula subordinada.

\subsubsection{Influencia de las lenguas de contacto en la época moderna}

Sin lugar a dudas, los contactos con las lenguas occidentales desde mediados del siglo XIX constituyen una de las características fundamentales del neojudeoespañol. Tanto el francés como el italiano han influido en la evolución de las construcciones condicionales, hecho que se observa en varios fenómenos: la difusión y consolidación del esquema $s i$ + imperfecto de indicativo + condicional, el conector causal-condicional si como 'puesto que' ( $c f$. it. siccome; vid. ej. 19 supra), el relativo ande I onde empleado en la locución en (el) ca(v)śo ande / onde ( $c f$. fr. au cas où, dans le cas où, pour le cas où; vid. ej. 4 supra), la preposición $a$ en $a$ (la) condición + que / a (la) condición + de + infinitivo ( $c f$. fr. à condition de [que]; it. a condizione che; vid. ejs. 7 y 9 supra), la preposición soto en soto la condición que ( $c f$. it. sotto condizione che; vid. ej. 8 supra) y el frecuente uso del gerundio preposicional (en + gerundio; vid. ej. 16 supra), especialmente para traducir formas del gérondif francés.

\section{CONCESIVIDAD}

\subsection{Aspectos teóricos}

De las numerosas definiciones de oración concesiva que se hallan en la bibliografía, citemos como punto de partida una de índole tradicional de la pluma de Samuel Gili GaYA (1985: 322):

Las oraciones subordinadas concesivas expresan una objeción o dificultad para el cumplimiento de lo que se dice en la oración principal; pero este obstáculo no impide su realización. Si decimos, por ejemplo, aunque haga mal tiempo, saldré, enunciamos el cumplimiento de la acción del 
verbo principal negando eficacia a la dificultad que la subordinada representa. Es como una condición que se considera desdeñable e inoperante para la realización del hecho.

Pero es más complicado, pues aparte de obstáculo, objeción, dificultad y condición desdeñable o inoperante se encuentran otros términos y explicaciones que pretenden definir la concesividad: expectativa que no se cumple, frustración de una expectativa, contraexpectativa, negación de un resultado normalmente esperable, cancelación de una relación de causa-efecto esperable, causa contraria, contra-causa o non-causa, etc. ${ }^{17}$ Las definiciones más difundidas son las que describen el contenido de las prótasis concesivas como un tipo de causa o condición que no conlleva la consecuencia o el efecto esperado, sino un resultado contrario. Por eso a veces la concesividad se interpreta como noción opuesta a la causalidad (cf. Di Meola 1998: 335-337), de ahí el empleo del calificativo inkausal por Hermodsson (1978: 61). En cualquier caso, la serie de definiciones pone de relieve dos características centrales de la concesividad: su complejidad lógico-semántica y las relaciones que guarda con otras nociones como la condicionalidad, la causalidad, la temporalidad y la adversativi$\operatorname{dad}^{18}$.

Un concepto relevante en relación con las oraciones concesivas es la presuposición ${ }^{19}$. Según Rivarola (1976: 4-5), «lo propio de una relación concesiva $[\ldots]$ es su carácter presuposicional: una relación concesiva no es sino una relación (lógicamente) conjuntiva entre dos frases que es contraria a una relación implicativa presupuesta entre una de ellas y la negación de la otra $»^{20}$. Por consiguiente, para interpretar una oración

17 Las definiciones completas se hallan en: DLM (s.v. Oración concesiva), IBBA (2010), Narbona JimÉnez (1990: 107-108), NGLE (2010: 3599) y Rofes Moliner (2012: 747).

18 Informaciones generales sobre las relaciones entre la concesividad y las demás nociones citadas se hallan, por ejemplo, en KöNIG (1988: 157-163) y KöNIG y EISENBERG (1984: 322-329).

19 Como introducción al mecanismo de la presuposición observable en las oraciones concesivas pueden consultarse los siguientes estudios: Di Meola (1998: 335-336), DLM (s.v. Presuposición, presuposición convencional/éxica), KÖNIG y EISENBERG (1984: 318319) y MAZZOLENI (1996: 48-49).

20 Véanse también Cortés Parazuelos (1992: 81-82), PASCH (1994: 27), Rivas (1989: 241) y Veiga y Mosteiro Louzao (2006: 108). 
concesiva como «Aunque llueve, Juan sale a pasear» (= enunciado concesivo concreto), hay que presuponer dos estados de cosas más generales, implícitamente presentes en la frase: en el contexto específico de la oración: «Si / cuando llueve, Juan normalmente no sale a pasear» (= norma particular); y en un sentido más genérico: «Si / cuando llueve, la gente normalmente no sale a pasear» (= norma general / conocimiento común). Es esta expectativa, basada en conocimientos extralingüísticos previos y activada -y al mismo tiempo negada- por el enunciado concesivo, la que permite establecer una relación contrastivo-concesiva entre dos situaciones o acontecimientos que por lo general se consideran incompatibles.

En español moderno, la conjunción concesiva por excelencia y de uso universal es aunque, a diferencia de otros nexos que han caído en desuso, entre ellos maguer(a) (que), mecanismo más antiguo para expresar concesividad en castellano e instrumento principal hasta por lo menos finales del siglo XIII, o nexos como pero (que) o comoquier que, que han perdido terreno sobre todo en los siglos XVI-XVII, a la par que incrementaba la frecuencia de aunque ${ }^{21}$. Al lado de aunque, el español actual conoce muchas otras formas que pueden expresar concesividad, por ejemplo las locuciones aun cuando, si bien, a pesar de (que) y pese $a$ (que) o algunas construcciones con gerundio (p. ej. aun + gerundio), participio (p. ej. participio $+y$ todo), infinitivo (p. ej. con + infinitivo), adjetivo o adverbio (p. ej. por + adjetivo / adverbio + oración relativa). En los últimos casos, igual que en otras construcciones sin conector concesivo específico ( $\mathrm{p}$. ej. en oraciones con la conjunción copulativa $y$ o en conexiones asindéticas), la interpretación concesiva solo puede ser una inferencia discursiva, dada la necesidad de un conector especializado para garantizar de modo inequívoco el significado concesivo de una oración. Son sobre todo otras construcciones circunstanciales las que pueden, dado el contexto adecuado, interpretarse como concesivas $^{22}$, mientras que no es realizable el procedimiento inverso: resultan

${ }^{21}$ Cf. Algeo (1972-1973: 533 y ss.), Cortés Parazuelos (1992: 187-212), Flamenco García (1999: 3840-3841), Narbona JimÉNEZ (1990: 108-110) y Rivarola (1976: 18-20, 70 y 80$)$.

${ }^{22}$ Esta característica no es privativa del español; en diversas lenguas hay conectores que pueden servir para expresar tanto nociones concesivas como otras relaciones 
imposibles las interpretaciones no concesivas de oraciones que llevan un nexo concesivo explícito, independientemente del contexto (KöNIG 1988: 150-151).

Por lo que atañe a la evolución diacrónica de las construcciones concesivas, hay que destacar que ninguno de los conectores concesivos del latín clásico continuó empleándose en las lenguas románicas. Por lo tanto, durante un primer período estas lenguas no disponían de nexos propiamente concesivos y tenían que recurrir a diversos mecanismos para crear un nuevo inventario de expresiones concesivas ${ }^{23}$. Por eso «[1] as conjunciones concesivas románicas son, en general, de aparición relativamente tardía y producto de la evolución interna de cada lengua» (RIvarola 1976: 14). Tanto esta formación tardía de las concesivas desde un punto de vista diacrónico -que halla su paralelo en el proceso de adquisición individual de lenguas- como la afinidad entre la concesividad y otras nociones son características compartidas por muchas lenguas ( $c f$. KöNIG 1988: 152; KöNIG 1985: 263-264; KöNIG y EISENBERG 1984: 322; WANG 1996: 16).

Los propios conectores concesivos subrayan las particularidades señaladas mediante su carácter muchas veces compuesto y de etimología transparente. Por lo general, los significados originales o anteriores de los componentes son significados más básicos que la concesividad, se identifican fácilmente y constituyen otra prueba más de que la concesividad se relaciona, tanto desde una perspectiva sincrónica como diacrónica, con otros ámbitos semánticos ( $c f$. KöNIG 1985: 263-264 y 280; KöNIG 1988: 156 y 163). Considerando las distintas fuentes de las que se han nutrido los conectores concesivos, se pueden distinguir diferentes grupos de conectores. A continuación se señalarán los más importantes y se ejemplificarán mediante algunos conectores en distintas lenguas ( $c f$. KöNIG 1985: 266-269; Kö-

semánticas (KöNIG 1988: 145). Referente a las estructuras que en español actual permiten expresar concesividad, sean o no conectores concesivos explícitos, véanse HERNANDO Cuadrado (1998: 129 y ss.), Lindschouw (2011: 100-106 y 246), Mazzoleni (1996: 52 y 59-60), NARBona JimÉNEZ (1990: 108-110) y Rivas (1990: 166).

23 Cf. Algeo (1972-1973), Bartol Hernández (1986: 153), Harris (1988: 67-78), Lindschouw (2011: 94-95 y 113-114), Martínez Moreno (1998: 403-404), Montero Cartelle (1992: 107), Narbona Jiménez (1990: 108) y Rivarola (1976: 14 y ss.). 
NIG 1988: 152-156; KöNIG y EISENBERG 1984: 323-325; LindSCHOUW 2011: 95-97):

1. Estructuras compuestas por un conector condicional, originalmente condicional o temporal y un elemento adicional enfático, bien un adjetivo, bien un adverbio: p. ej. si bien, incluso si, quand même, même si, sebbene, even though, even so, wenngleich, auch wenn, obschon, obwohl, etc.

2. Construcciones formadas por un adverbio temporal y, por ejemplo, la conjunción que, que expresan la co-ocurrencia o co-existencia de los contenidos expresados en las dos cláusulas y, con ello, la afinidad entre la concesividad y la simultaneidad: p. ej. aunque, ya que, encore que, cependant, ancorché, anche che, ainda que, even now, still, dennoch, indessen, etc.

3. Expresiones derivadas de nociones como 'contrariedad', 'divergencia' o 'desprecio', que han sufrido un proceso de bleaching para pasar de un significado concreto a otro más abstracto: $\mathrm{p}$. ej. a pesar de (que), pese a (que), a despecho de, a riesgo de, malgré (que), en dépit de, au mépris de, malgrado (che), in spite of, despite, trotz, trotzdem, etc.

4. Construcciones que ponen de manifiesto la relación existente entre la concesividad y la cuantificación universal o de libre elección: p. ej. toutefois, tout ... que, however, anyway, although, allerdings, etc.

5. Expresiones de escalaridad: p. ej. preposición + adjetivo o adverbio + que (p. ej. por más que), etc.

\subsection{Las oraciones concesivas en judeoespañol moderno}

\subsubsection{Distribución cuantitativa de los conectores concesivos}

Tal vez lo más llamativo en relación con las oraciones concesivas en judeoespañol moderno sea que no conocen un único mecanismo claramente mayoritario. Por eso no solo se diferencian de las concesivas en español moderno, que en la mayor parte de los casos se construyen con 
la conjunción aunque, sino también de las oraciones condicionales, que tanto en castellano como en judeoespañol muestran una preferencia muy marcada por el empleo de la conjunción si.

A grandes rasgos, los mecanismos concesivos empleados en los textos estudiados se distribuyen según se deduce del siguiente gráfico:
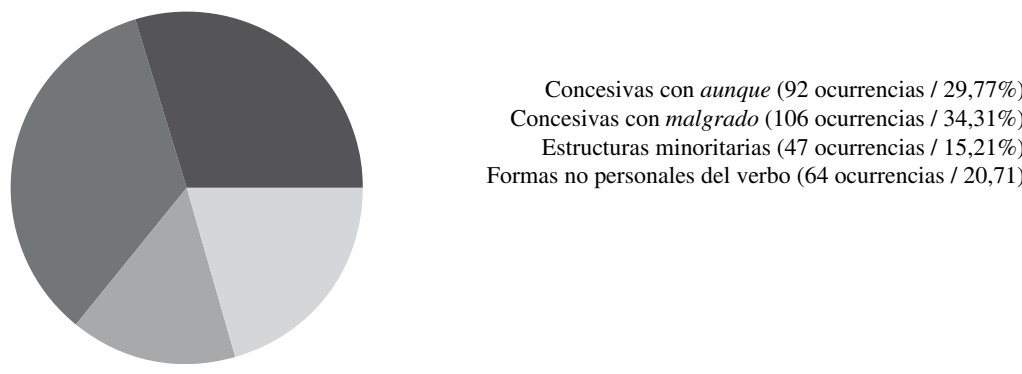

Gráfico 4. Distribución cuantitativa de los mecanismos concesivos.

Cada uno de los dos conectores mayoritarios, aunque y malgrado (que), se emplea aproximadamente en un tercio de los casos, con lo que ni juntos representan un porcentaje tan alto como las oraciones con $s i$ en el caso de las condicionales. Una serie de mecanismos adicionales (estructuras minoritarias y las ocurrencias concesivas del gerundio y del infinitivo) cubren el último tercio.

De los dos conectores más habituales, malgrado (que) es el más frecuente (vid. ejs. 36-38). Se emplea en un 34,31\% de las oraciones concesivas, frente al 29,77\% correspondiente a aunque (ejs. 39-41). Malgrado (que) tiene un carácter claramente innovador: es un conector propio de la época moderna, no documentado en textos sefardíes del siglo XVIII, y demuestra la influencia de las lenguas occidentales de contacto en el campo de la concesividad desde mediados del siglo XIX ( $c f$. italiano malgrado [che] y francés malgré [que]). Estamos, pues, ante una doble diferencia frente al castellano moderno: dos estructuras concesivas mayoritarias en los textos sefardíes se oponen a la predominancia de aunque en español, y la mayor cifra de ocurrencias entre las concesivas judeoespañolas no le corresponde a aunque, sino a malgrado (que). 
(36) Hoy es la primera veź de cuando estó aquí que so en estado de hablarvos en la lingua que vośotros habláš y malgrado que -según lo vešdaínda non hablo tan coriente según lo deśeo, con todo me es alegre que ya puedo empezar a explicarme con vośotros de tiempo a tiempo sobre mis ideas y mis conocencias sobre los sujetos que preocupan nuestro ŝiḅur ['comunidad']. (EJp6,41)

(37) El famośo poliz amator estaba muy muncho rabiado. Malgrado todos sus esforzos, malgrado todas sus búšquidas, él no topaba nada. $(\mathrm{JJn} 5,8)$

(38) Malgrado todo esperan pueder salvarlo. (AVp13,3b)

(39) Aunque las piramidas son hoy arancadas y deśregladas, con todo ellas son muy admiradas por los viajadores que vienen cada año de todas las partes del mundo vis̀itar esta masa colosal. (YERp5,34a-b)

(40) Él estaba en pies, las manos arugadas y apretadas y los ojos, aun-que secos, brillando como vidros. (BGn4,12)

(41) Aun que esta tortura me había tomado todas mis fuerzas fui bastante corajośo por disculpar a mi padre, y con toda mi ỵoź grití: "Mi padre es inocente." (APRn,11)

El resto de los mecanismos concesivos empleados en MemTet constituyen casos más bien aislados y poco representativos. Primero, a veces la conjunción condicional si transmite matices concesivos, hecho permitido por el parentesco lógico entre la condicionalidad y la concesividad (ej. 42). Segundo, se hallan diez ocurrencias de la conjunción cuantunque, italianismo de adopción reciente empleado solo en textos publicados en Salónica, sobre todo en la prensa (ej. 43). Tercero, aparecen fórmulas muy poco difundidas con peśar y las estructuras bien que y a regreto (ejs. 44-46), y por último, las formas impersonales del verbo que pueden adquirir funciones concesivas. En el caso del gerundio, la estructura más usada es el gerundio preposicional reforzado mediante todo (todo en + gerundio), que refleja el modelo francés tout en + gérondif (ej. 47); por lo que concierne al infinitivo, la construcción más frecuente es sin + infinitivo, muchas veces con el verbo querer / quierer (ej. 48).

(42) Optimistas como las almas sémpliches, venturośas como la ĝente sin historia, las mujeres judías de Salonico sonreían siempre a la vida, si la vida non les sonreía siempre. (FAMc,4) 
(43) La Greĉia quis̀o tocar a los diritos de muestro país. El Governo de su Maestad Imperial el Sultán, cuantunque paćiguośo de natura, fue obligado de castigar al chico reinado heleno, por haćerse respectar. $(\mathrm{AVp} 3,3 \mathrm{a})$

(44) Por nośotros ĵidiós del Oriente dićen que somos una familla de mudos, un grupo de gentes que no tienen lengua, no tiene literatura. Ajuntemos a esta doḅle negación aínda una trecera: nośotros no tenemos historia. ¡Y a peśar de este fato, yo también tuve el coraje de combidarvos ['invitaros'] a una conferencia y de denunciar ['anunciar'] como sujeto un títolo que promete enormemente mucho! (MUJc,2)

(45) El muśeo agricol y źoolóǵico de la organiźación ŝiyonista, bien que fondado atrás muy pocos años, es ya rico en colecciones y se distingüe por el clasamiento mucho rico de sus objétos. Su local es un model en su género. (MAKp25,51)

(46) Antes miśmo que el critic venga dećir su vierbo y apreciar su talento de Šalom 'Alejem, ya lo recibió y lo acceptó el público jiidió como un musafir ['huésped', 'invitado'] distinguiido de alta estima del cual se desparte con mucha dificultad y a regreto. (JIDp25,38a)

(47) ¡Oh! Nunca por seguro. Siendo ¿qué provecho trae la riqueźa cuando no poder goźarla? ... Todo en siendo probe, ¡vós soš dunque más rico que vuestro većino rico! (YERp4,30a-b)

(48) Una rara fuerza de imitación. Sin quiererlo, dice él, yo imitaba los gestos y los movimientos de ciertos personajes sin nada mancar. (JIDp25,37a)

\subsubsection{Tipos textuales y factores contextuales}

Por lo que atañe a los tipos textuales, constatamos una predominancia de la narrativa tanto en aunque (47,83\%) como en malgrado (que) (40,56\%). El segundo tipo textual más frecuente es la prensa, que sobre todo en el caso de malgrado (que) alcanza un porcentaje considerable de un 39,62\% (frente a un $22,83 \%$ en aunque). Por el contrario, los porcentajes relativos al teatro son más bajos: un $16,30 \%$ en el caso de aunque y tan solo un $4,72 \%$ en el caso de malgrado (que). En los textos humorísticos, incluso, no se halla ninguna construcción concesiva. La distribución mencionada permite sacar varias conclusiones: primero, las concesivas destacan como 
mecanismo típico de la lengua escrita formal, mientras que las condicionales también son muy frecuentes en el teatro y asimismo aparecen en los textos humorísticos. Es de suponer que esta diferencia está ligada a la postulada complejidad mayor y al empleo más restringido en la lengua oral de las concesivas frente a las condicionales. Segundo, el porcentaje alto de ejemplos periodísticos entre las concesivas con malgrado (que) confirma el carácter innovador del conector, que entró al mundo sefardí por vía escrita y comenzó a difundirse en la prensa por medio de autores y redactores que eran conscientes de su papel decisivo en la difusión no solo de noticias, sino también de novedades culturales y lingüísticas ( $c f$. ScHMID 2006a: 8-9 y SCHMID 2008: 69-71). Y tercero, podemos resumir que la conjunción aunque es el conector concesivo menos especializado: sus porcentajes de aparición según tipos textuales no divergen tanto de los porcentajes relativos al corpus MemTet que los correspondientes a malgrado (que).

En cuanto a la procedencia de las oraciones, la ciudad que más destaca es Salónica. En tiempos del Imperio Otomano los contactos de esta ciudad portuaria con Italia y con la lengua italiana eran más intensos que en otros lugares del Imperio, «por ser el italiano la lengua del comercio en los puertos levantinos» (ScHMID 2008: 62). Por eso desde siglos anteriores y hasta la época moderna «es indudable la fuerte influencia del italiano en la variedad salonicense del judeoespañol» (BüRKI 2012: 325) ${ }^{24}$. Puesto que malgrado (que) se emplea con preferencia en textos salonicenses (un 59,43\% de los casos), proponemos interpretarlo como italianismo más que como galicismo. También todas las ocurrencias de la conjunción italiana cuantunque proceden de textos publicados en Salónica, más de la mitad de artículos periodísticos. La ausencia tanto de malgrado (que) como de cuantunque en textos sefardíes clásicos permite calificarlos de neologismos modernos, hipótesis corroborada por la distinta repartición cronológica de las concesivas con aunque y malgrado (que): el porcentaje relativo de las ocurrencias de malgrado (que) es más alto en los textos del siglo XX que en los que datan del siglo anterior.

${ }^{24}$ Desde el comienzo de la diáspora sefardí a la ciudad de Salónica le correspondía un papel destacado. Los sefardíes representaban la mayoría de la población hasta comienzos del siglo Xx, por lo cual su aportación fue decisiva en cualquier ámbito de la vida. Debido a la importancia de Salónica para el comercio mediterráneo, los contactos con Italia y con la lengua italiana siempre han sido especialmente fuertes. Sobre la diáspora sefardí en Salónica pueden consultarse BARNAÏ (1992b), EJ (s.v. Salonika [Thessaloniki]) y WAHL (1997); para la época moderna en particular, BÜRKI (2003; 2012: 47-49) y KEREM (1999). 
Frente a la predominancia de malgrado (que) en los textos salonicenses, varios textos emplean con preferencia o exclusividad la conjunción aunque: por una parte, la obra teatral El Angustiador, los artículos sacados del periódico La Alvorada (ambos publicados en Sarajevo por Abraham Aaron Cappon) y la narración Los Maranos. En los tres casos la elección consciente de la conjunción aunque es un indicio de la preferencia de los autores o editores por soluciones lingüísticas hispanas ${ }^{25}$. Por otra parte, también las comedias sefardíes resaltan por el uso exclusivo de aunque para expresar concesividad, lo cual en este caso consideramos como muestra de su lenguaje más informal, familiar y oral, que prefiere emplear la conjunción más generalizada.

\subsubsection{Variación sintáctica}

Por lo que respecta a los usos verbales en las prótasis concesivas estudiadas, de nuevo constatamos una predilección por formas verbales del modo indicativo. Dicha preferencia es menos sorprendente que en las oraciones condicionales, puesto que las concesivas suelen describir situaciones y acciones reales, las cuales también en español se expresan mediante formas indicativas.

Si nos fijamos en los conectores concesivos mayoritarios, tanto aunque como malgrado que por lo general van acompañados por verbos en indicativo, salvo unas ocurrencias de aunque con el llamado subjuntivo polémico,

${ }^{25}$ Otros investigadores ya han observado que la lengua de Abraham A. Cappon (Ruschuk, 1853 - Sarajevo, 1930) se caracteriza por una tendencia hispanizante (vid., p. ej., SubAK 1906: 133; Romero 1992: 278-279; SÁnchez 2008: 206; SCHMID 2010). Por ejemplo, Cappon emplea numerosos hispanismos léxicos, al lado de galicismos e italianismos, frecuentes en neojudeoespañol en general; de esta forma se explica su preferencia por emplear la conjunción aunque en las oraciones concesivas. En las condicionales, por su parte, llama la atención el frecuente empleo del esquema $s i+$ condicional + condicional, sobre todo en las condicionales irreales; por el contrario, apenas aparecen los esquemas mayoritarios del corpus, esto es, $s i+$ imperfecto de indicativo + condicional y $s i+$ imperfecto de indicativo + imperfecto de indicativo. Es de suponer que Cappon considera el esquema simétrico con formas del condicional como más "peninsular" que los esquemas con formas del imperfecto de indicativo; tal vez estos últimos le parezcan demasiado "francófilos", pese a que, según hemos señalado, la consolidación del uso modal del imperfecto en las condicionales es una solución propia del judeoespañol, difundida ya en la época clásica. 
es decir, usos del subjuntivo para expresar hechos reales ${ }^{26}$. En las concesivas con malgrado que, la combinación con el modo indicativo es más llamativa porque se opone a los usos normativos de malgrado che en italiano y de malgré que en francés ${ }^{27}$. Lo mismo se observa en la conjunción cuantunque, que en italiano de nuevo se construye con el modo congiuntivo (Díaz PADILLA 1999: 891; GarzantiDiz, s.v. quantunque), mientras que en judeoespañol, cuando introduce sintagmas verbales, lleva el verbo en indicativo. También en las oraciones concesivas, pues, se hace notar una predilección de la lengua sefardí por el modo indicativo, así por ejemplo en los conectores adoptados de otras lenguas románicas que allí rigen el modo subjuntivo.

Otra diferencia sintáctica fundamental entre las concesivas con aunque y con malgrado (que) es la siguiente: mientras que las primeras en la gran mayoría de los casos introducen sintagmas verbales (78 de las 92 ocurrencias), las segundas prefieren la combinación con sintagmas nominales (96 de las 106 ocurrencias). La tendencia señalada para malgrado hace pensar en las frecuentes construcciones nominales introducidas por a pesar de en español, locución que apenas aparece en MemTet. A modo de conclusión, se puede resumir que el empleo de aunque o malgrado (que) en las oraciones concesivas se debe a múltiples factores, tanto lingüísticos como extralingüísticos (procedencia y datación de los ejemplos, tipos textuales, autoría, etc.).

\subsubsection{Influencia de las lenguas de contacto en la época moderna}

Igual que en el campo de la condicionalidad, también en las oraciones concesivas se detectan influencias de las dos lenguas de contacto más importantes en la época moderna. Como calco del francés destaca el gerundio preposicional en + gerundio, reforzado muchas veces por el pronombre indefinido todo antepuesto: todo en + gerundio (vid. ej. 47 supra). Es la estructura con gerundio más frecuente para expresar concesividad y demuestra uno de los usos del gérondif francés. También el

${ }^{26}$ El primero en emplear el término de subjuntivo polémico fue VALLEJo (1922). Lo retoman, por ejemplo, BARTOL Hernández (1986: 146) y SECO (1988: 247), hablando de concesivas polémicas.

27 Véanse, para el italiano, GarzantiDiz (s.v. malgrado) y ZingarelliVoc (s.v. malgrado); para el francés, GREvisse (1980: 1361) y KLARE (1958: 62-66 y 138). 
conector a regreto posiblemente refleja un modelo francés (à regret; vid. ej. 46 supra). Del italiano, por su parte, el judeoespañol ha adoptado los conectores concesivos malgrado (que) -tal vez apoyado por el francés malgré (que)- у cuantunque (vid. ejs. 36-38 y 43 supra). Adicionalmente, sería posible pensar en una influencia fonética del italiano en la variante monoptongada de aunque, esto es, anque.

\section{CATEgORÍAS PERIFÉRICAS (I): LAS ORACIONES PSEUDOCONDICIONALES EN JUDEOESPAÑOL MODERNO}

Como se ha adelantado, existen ciertas construcciones cuyo aspecto formal es idéntico al de las oraciones condicionales, pero que desde una perspectiva semántico-pragmática no se ajustan del todo a la definición prototípica de estas. Por un lado, tales oraciones coinciden formalmente con las auténticas condicionales, es decir, están compuestas por un sintagma subordinado introducido por un conector condicional, mayormente la conjunción si, y un sintagma principal; por otro lado, sin embargo, no reflejan el modelo lógico de las construcciones condicionales, según el cual la apódosis expresa la consecuencia de la condición expuesta en la prótasis ( $c f$. Esbozo 1973: 554 y RodríGuez Rosique 2008: 151). Dichas oraciones, en las que la semántica condicional es secundaria o (prácticamente) inexistente y de las que hemos detectado 162 ocurrencias en los textos sefardíes analizados, se pueden reunir bajo el concepto de oraciones pseudocondicionales ${ }^{28}$.

Partiendo de los datos que nos ofrece el corpus MemTet, resulta posible diferenciar cuatro subcategorías de las oraciones pseudocondicionales, que se diferencian sobre todo en el nivel del significado: las pseudocondicionales comparativas (104 ocurrencias), las explicativas (39), las contrastivas (11) y las expresivas (8). Las oraciones cuya semántica se

28 Cf., por ejemplo, Julián Mariscal (2007), NGLE (2010: 3560-3564) y SAntana Marrero (2003: 27-31). Otros investigadores prefieren hablar de oraciones condicionales formales, así Marcos Marín, Satorre Grau y Viejo Sánchez (2002: 454-455). Para un estudio preliminar sobre las oraciones pseudocondicionales en judeoespañol, véase SCHLUMPF (2012b). 
sitúa entre la condicionalidad y la concesividad se tratarán en el apdo. 8 dedicado a las oraciones condicionales concesivas.

\subsection{Pseudocondicionales comparativas}

Las pseudocondicionales comparativas expresan una comparación hipotética, mayormente a través del adverbio modal como. En los textos sefardíes aparecen las siguientes estructuras: como si (60 ocurrencias), como que (34), como + gerundio simple o compuesto (8) y dos construcciones de gradación $+s i+$ verbo en subjuntivo.

(49) Sí, yo vo ir a punto y defender tu cauśa como [la defendería] si fuera mía. (FABt,376a)

(50) El chico sentía atantivamente, su corazón se aǵitaba y batía tan fuerte como que quería saltar de su lugar. (SEFn,45b)

(51) Pálido y temblando de todos sus miembros él se asentó y de una yoź baj̆a como hablando en durmiendo él dećía: me vo a ir de aquí... me vo... a... ir. Aquí no tengo a ningunos, ni madre ni hermana... (SEFn,48a)

(52) Él había descubierto un misterio cas̀i impenetrable y esto lo contentaba muncho más que si le hubieran dado todo el oro del mundo. (JJn3,15)

La locución mayoritaria es como si, elemento introductor prototípico de esta clase de oraciones también en castellano. La condición expresada en las construcciones comparativas suele ser de tipo irreal, por lo que en español estándar únicamente puede expresarse mediante formas verbales del imperfecto o pluscuamperfecto de subjuntivo ( $c f$., p. ej., García MoReno 2004: 330-331; Montolío 1999a: 3679; Veiga y Mosteiro LouZao 2006: 200). También en judeoespañol el carácter irreal de las comparaciones se refleja de modo más claro en las formas verbales que en las demás oraciones (pseudo)condicionales: un 35,79\% de las construcciones comparativas con verbo conjugado en la prótasis emplea el modo subjuntivo y el porcentaje correspondiente a las oraciones con como si incluso asciende al 50\%. En cuanto a los géneros textuales, las oraciones comparativas predominan en la narrativa $(69,23 \%)$, donde sirven para ejemplificar o aclarar una narración o descripción. 


\subsection{Pseudocondicionales explicativas}

En las pseudocondicionales explicativas la función de la apódosis es expresar la causa o justificación de lo enunciado en la prótasis: si p, es porque q (cf. Montolío 1999a: 3674 y CANo Aguilar 2011: 42-45). El esquema implicativo funciona al revés que en las condicionales prototípicas, donde la condición siempre se expresa en la prótasis: en una oración como «Si llora, seguramente estará triste», lo que se presenta como la causa supuesta del llanto es la tristeza (NGLE 2010: 3552).

En cuanto a los rasgos formales, en primer lugar es de señalar que en casi todas las oraciones explicativas la cláusula principal va introducida por el verbo copulativo ser (en 36 de las 39 ocurrencias). Otros elementos subrayan la función causal de la apódosis (cf. Montolío 1999a: 3674); por ejemplo, muchas veces el verbo ser va acompañado por una conjunción o preposición que manifiesta la función explicativa de dicho sintagma: porque, por que, que 'porque', para, por (a veces con el sentido de 'para') y con.

(53) Si yo te guardo, es porque me apïado de ti, porque te amo, mi cara y desmeollada ['turbada', 'distraída'] crïatura, porque tú sos mi orgullo, mi amada, mi eleva. (MARn,9)

(54) Si yo estó en este momento en vuestra caśa, es que una cośa me puǰó a tener confienza en vós. (SEDn,6-7)

(55) Si las mujeres toman cuido y intereso por sus hermośura, es por lo que ellas saben que los hombres non las aman que por esto. (PURv,10)

(56) No, vo lo aseguro... Si pude ganar su corazón fue con la altigüeźa, no es ahora la hora de reḅajarme. (FABt,381b)

En otros casos el matiz explicativo se atestigua en el nivel léxico: por un lado, es frecuente que en la frase principal se explicite quién / qué es la causante o quién / qué tiene la culpa -o no la tiene- de la acción expresada en la frase subordinada. Por otro lado, varios sintagmas principales van introducidos por locuciones como es a cavśa de, es dovido a, es gracias a y esto proviene de, que señalan el sentido explicativo de la oración.

(57) ¡Non es su culpa si non vido dingún libro o dingún jornal que él puedía entender! (AVp3,7a) 
(58) Si al punto de vista económico la situación del jiidió en Palestina es hoy bastante satisfaćiente, [...] esto cale reconocerlo es dobido a lo que se llama la cuarta 'aliyá ${ }^{29},[\ldots]$. (MAKd25,17)

(59) Después vienen a dećir que si los jidiós se enriquecen es gracias a la uśura. (NACp1,9b)

En cuanto a la distribución de las pseudocondicionales explicativas según tipos textuales, llama la atención el porcentaje relativamente alto de los discursos, indicio del lenguaje más bien formal al que pertenecen estas oraciones.

\subsection{Pseudocondicionales contrastivas}

Las pseudocondicionales contrastivas no manifiestan una relación condicional, sino una oposición del tipo por un lado $p$, por otro lado $q \mathrm{o}$ $p$ frente a $q$. La frase principal siempre está pospuesta a la frase subordinada (cf. Santana Marrero 2003: 29-30) y el contraste se refleja de modo explícito en el texto ( $c f$. CANo Agullar 2011: 49; Julián MarisCal 2007: 574; NGLE 2010: 3563), sea en el nivel léxico mediante términos semánticamente opuestos (p. ej.: «una influenza favorable» - «un grave inconveniente»; «espirtu» - «cuerpo»), sea en el nivel gramatical mediante una negación (p. ej.: «es facil» - «no lo es»; «es la primera vez» - «non es [...] la primera vez»).

(60) Si esta imigración tuvo una influenza favorable en un cierto senso ['sentido'], por contra, tiene un grave inconveniente. (MAKd25,18)

(61) Si su espirtu era despierto, su cuerpo no lo era; él probó de gritar, ma ningún son no pudo salir ni pasar por su garón ['garganta']. (BGn7,25)

(62) La experienza nos enseña que la rectitud y la preĉiśión de las teorías se encontran ralamente en las descorajantes realidades de las batallas de la vida, y si es facil de criticar y de aderezar oḅservaciones, no lo es tanto de corijar y de reformar. (MEJd,35)

${ }^{29}$ Aliyá ('ascenso'): palabra hebrea empleada en la época moderna para designar las oleadas de inmigración a Palestina / Israel. La Cuarta Aliyá tuvo lugar entre 1924 y 1929 (cf. Britannica, s.v. aliyah; BunisLex 3142; NehamaDict, s.v. alíya). 
(63) Si es la primera vez que un hecho semejante viene a ser publicado en una gaćeta, non es por seguro la primera vez que acontece. (EPp83,210b)

Alrededor del $45 \%$ de las pseudocondicionales contrastivas procede de conferencias y discursos (frente al $11 \%$ que constituyen dichos tipos textuales en el corpus MemTet); otras se hallan en artículos periodísticos con funciones discursivas parecidas. Deducimos, por tanto, que las pseudocondicionales contrastivas son propias de un registro más bien formal y de textos estilísticamente elaborados, que suelen tener una intención práctico-didáctica.

\subsection{Pseudocondicionales expresivas}

Como indica su nombre, las pseudocondicionales expresivas o enfáticas tienen una función predominantemente expresiva: manifiestan «una mayor participación del hablante en la emoción o sentimiento que comunica[n]» (Alarcos Llorach 2002: 478). Casi siempre es posible omitir la conjunción si sin que la frase pierda su significado o resulte agramatical ( $c f$. SAntana Marrero 2003: 29). No obstante, este uso de si suele dotarles a las oraciones un matiz semántico o discursivo adicional, por ejemplo, de sorpresa, réplica u oposición ( $c f$. Montolío 1999b).

(64) [...] en Pésah entero eśiste una grande idea: idea de la tráǵica eternela en la vida del pueblo jidió, idea de la reǵeneración eternela de este pueblo [...]. Tala es la fiesta de Pésah, ma ¿si non es ansí también toda la vida del judaíśmo? (EJp6,41)

Más de la mitad de las pseudocondicionales expresivas forman parte de exclamaciones o preguntas en estilo directo, o sea, pertenecen a la lengua hablada y a un registro mayormente coloquial. No sorprende, por tanto, que todas proceden, bien de textos dramáticos $(62,50 \%)$, bien de pasajes dialogales en textos narrativos o periodísticos. 


\section{CATEgORÍAS PERIFÉRICAS (II): LAS ORACIONES CONDICIONALES CONCE- SIVAS EN JUDEOESPAÑOL MODERNO}

Desde una perspectiva tipológica, las oraciones condicionales concesivas o concesivo-condicionales se sitúan entre las condicionales y las concesivas $^{30}$. De las condicionales se diferencian, principalmente, por las características de la prótasis, que no ofrece una sola condición, sino una serie de condiciones ( $c f$. HASPELMATH y KöNIG 1998: 564-566; KöNIG 1985: 264; KöNIG 1991: 635; KöNIG y EISENBERG 1984: 315). Esta serie de condiciones puede expresarse mediante una estructura escalar, una disyunción o un cuantificador universal ${ }^{31}$ :

Estructura escalar: Incluso si hay temporal, Antonio sale a pescar.

Disyunción: Llueva o no llueva, siempre saca el perro a pasear.

Cuantificación universal: Este chico, dondequiera que vaya, siempre hará amistades.

(Ejemplos tomados de Flamenco García 1999: 3843, 3847 y 3848).

Además, a diferencia de las oraciones condicionales, las concesivo-condicionales afirman que el contenido de la apódosis se realiza bajo cualquiera de las condiciones incluidas en la prótasis, de ahí los términos de irrelevance (concessive) conditionals o Irrelevanzkonditionale (KöNIG 1985: 264; KöNIG 1991: 635). Este es uno de los rasgos que las condicionales concesivas comparten con las concesivas: el carácter factual de la apódosis. Por el contrario, las prótasis solo tienen carácter factual en las concesivas, mientras que en las concesivo-condicionales son de tipo hipotético. Resumiendo, KöNIG (1985: 265) y KÖNIG y VAN DER Auwera (1988: 106) explican que las condicionales no implican la factualidad ni de la prótasis ni de la apódosis, mientras que las condicionales concesivas implican la factualidad de la apódosis, y las concesivas, la de ambas cláusulas; las concesivo-condicionales, pues, se hallan en una posición intermedia.

30 Para un análisis extenso de las condicionales concesivas remitimos a RoDRíGUEZ Rosique (2008). Como estudio preliminar sobre el tema en judeoespañol puede consultarse SCHLUMPF (2014).

31 Para esta clasificación de las condicionales concesivas, véase especialmente el trabajo de HASPELMATH y KöNIG (1998). 
Otro rasgo compartido por las concesivo-condicionales y las concesivas es que la serie de condiciones incluidas en la prótasis contiene como mínimo una condición que resulta desfavorable para -o incompatible con- la circunstancia expresada en la apódosis, o cuya posible realización provoca una sorpresa en relación con el contenido de esta última ( $c f$. KÖNIG 1988: 147-148; KöNIG y EISENBERG 1984: 316-317).

La semántica compleja de las condicionales concesivas, situadas en un cruce conceptual entre la condicionalidad y la concesividad, se refleja en los rasgos formales de sus conectores prototípicos, que -igual que los concesivos- destacan por su formación tardía en la historia de las lenguas, su estructura compuesta y una etimología transparente. Muchas estructuras concesivo-condicionales se originan en otras clases oracionales (condicionales, interrogativas, relativas, etc.) y los conectores concesivocondicionales pueden convertirse en conectores concesivos puros $(c f$. KÖNIG 1985: 269-274; KÖNIG 1988: 158-159; KöNIG y EISENBERG 1984: 325-327; SÁNCHEZ LÓPEZ 1995: 120-121).

Veamos a continuación los tres tipos de condicionales concesivas y sus usos en judeoespañol moderno.

\subsection{Condicionales concesivas escalares}

En primer lugar, las condicionales concesivas escalares o graduales ( $c f$. Haspelmath y KöNIG 1998: 584-593) abren en la prótasis una escala de varios valores posibles y «sitúan la expresión sobre la que inciden en un punto o nivel determinado -concretamente, uno de los extremos y el menos previsible-» (Flamenco García 1999: 3843). Incluso más que los otros tipos, las concesivo-condicionales escalares se caracterizan por su estructura formal transparente y una semántica composicional. Las lenguas finitas suelen expresarlas mediante conjunciones subordinantes que van precedidas por una partícula de foco -que a veces también puede posponerse-, así por ejemplo incluso si o ni siquiera en castellano, even if en inglés, même si / si même en francés, se anche / anche se en italiano, selbst wenn, auch wenn / wenn auch en alemán, mesmo que, ainda que y nem que en portugués, etc. Como se ve, en muchas lenguas el conector usado en combinación 
con la partícula de foco coincide con un conector condicional. Dicho elemento focal actualiza la serie de condiciones implicadas en la prótasis, sitúa el elemento focalizado en el extremo de esta «hipotética escala de probabilidad» (FLAMENCO GARCíA 1999: 3843) y convierte una oración condicional en otra de tipo concesivo-condicional ( $c f$. Haspelmath y KöNig 1998: 576; KöNig 1985: 270).

En los textos sefardíes hemos encontrado 86 oraciones concesivo-condicionales escalares. No aparece nunca la locución prototípica del español, incluso si, ni su variante negativa, ni siquiera. En cambio, el judeoespañol ha tomado prestadas expresiones de otras lenguas: por una parte, el hebraísmo afilú 'incluso (si)', 'aun cuando', 'aun así' (BunisLex 263), cuyo uso ya está documentado en textos sefardíes del siglo XVIII (15 ocurrencias; $c f$. ej. 65) ${ }^{32}$; por otra parte, las locuciones miśmo si / si miśmo y miśmo que, calcos del francés même si / si même y même que (30 y 5 ocurrencias, respectivamente; $c f$. ejs. 66 y 67). Considerando las frecuencias de uso y adoptando una perspectiva diacrónica, observamos un desplazamiento entre el siglo XVIII y la época moderna, que favorece el neologismo galo frente al hebraísmo, reflejo de un general cambio de actitud en el mundo sefardí moderno.

(65) Afilú cuando se trata de haćinura ['enfermedad'] sémpliche, la madre, que tiene menester de repośo, es obligada de despertarse cada punto porque el chico está despierto o llora o quiere la teta [...]. (EPp83,211a)

(66) Yo vo ir con vós, miśmo si me vaš a llevar al inferno. (BGn7,21)

(67) Miśmo que me aroguen mucho y que se metan de ĝinollos delantre de mí, yo no vo a dar más moneda... (MAZt,49b)

Entre las estructuras escalares minoritarias aparecen las siguientes: dos ocurrencias aisladas de si anque -nótese la coincidencia fónica con el italiano se anche / anche se- (ej. 68); para la variante negativa, construcciones con miśmo, además de ni menos, ni manco y ni si (p. ej., 69 y 70); y construcciones con subjuntivo (ej. 71).

32 En yidis, lengua de los judíos asquenazíes del centro y Este de Europa, se usa el mismo hebraísmo, en forma de afile o afile ven (cf. BirnBAum 2011: 109; HaSPELMATH y KöNIG 1998: 596). 
(68) J́ośef.- Si anque va topar mijor que ti, no me va espośar ['no se va a casar conmigo']. (TSt14,4c)

(69) «La situación de los jidiós en Rumanía es muy estremecible, dinguna esperanza de luź non se vee ni mismo de lejos, non hay dinguna esperanza que la situación se mijoreará en estos días. Con todo esto, es un crimen de encorajar a los jidiós de Rumanía a salir del país. [...]» (EJp6,43)

(70) El Šastre (Solo). - [...] ¡Yo te la vo a mandar la ropa hasta caśa! Ni si te veo enpingado ${ }^{33}$ no te fío yo a ti un tenc ${ }^{34}$. (TSt3,148)

(71) Y como ya lo debéš saber, los ladrones, sean ellos los más haḅiles, heśitan ['vacilan'] a haćer sus colpo cuando topan en sus camino enemigos semejantes... (LXn,43)

\subsection{Condicionales concesivas alternativas}

En segundo lugar, las condicionales concesivas alternativas o polares ( $c f$. Haspelmath y KÖNIG 1998: 594-604) expresan dos condiciones alternativas, sean dos opciones distintas, sean una condición y su negación. En otras palabras, se trata de la combinación de dos prótasis condicionales que «presentan dos posibles alternativas que conducen a la misma conclusión»; por eso «no existe obstáculo posible para el cumplimiento del consecuente» (Flamenco García 1999: 3846).

Las concesivo-condicionales alternativas pueden manifestarse a través de diversas estructuras lingüísticas. Uno de los procedimientos más frecuentes en lenguas como el español es el empleo del modo subjuntivo, bien en combinación con un conector condicional o concesivo (p. ej.: «Aunque llueva o salga el sol, saldremos»), bien mediante la mera unión de dos cláusulas conectadas a través de la conjunción disyuntiva $o$ (p. ej.: «Llueva o brille el sol, saldremos»; «Te guste o no te guste, ...») (cf. HASPELMATH y KÖNIG 1998: 595-596 у 598-599; NGLE 2010: 3623-3624). En muchas lenguas que conocen este tipo de concesivo-condicionales alternativas es el único o más habitual. En otras, por ejemplo en lenguas

33 Por el contexto parece error por enpennado ‘empeñado' (MARTín HeREDIA 1990, vol. I: 58, n. 7$)$.

34 Tenk: quizá moneda de escaso valor, 'perra'; cf. turco teng 'pequeño', 'escaso' (Martín Heredia 1990, vol. II: «Glosario», s.v. tenk I). 
germánicas como el alemán o balto-eslavas como el ruso, las condicionales concesivas polares pueden coincidir con las interrogativas indirectas (p. ej. en alemán: «Ob ich gewinne oder verliere, Badminton macht mir Spass») ( $c f$. Haspelmath y KöNIG 1998: 596). También elementos que significan 'you want', 'it may be', 'let it be' o 'be it' pueden expresar polaridad concesivo-condicional (p. ej. en italiano: «Sia che piova sia che faccia bello, usciremo») (HASPELMATH y KÖNIG 1998: 599-601). Por último, a veces no se explicita ni la subordinación ni la disyunción -entonces el segundo elemento suele ser la negación del primero- o no hay negación sino oposición de dos elementos contrapuestos (p. ej. en inglés: «Right or wrong, it is my country») ( $c f$. HASPELMATH y KöNIG 1998: 602-604).

En judeoespañol, casi todas las 22 concesivo-condicionales alternativas emplean el modo subjuntivo. Mayormente se trata de estructuras reduplicadas a partir del verbo ser, aunque a veces está elidida la segunda forma verbal, por ejemplo para expresar una opción complementaria o la negación de la primera alternativa.

(72) Los jidiós son los primeros a sufrir cuando hay reỵuelta sea que vencen los almanes, sea que vencen los tcheques. Es por esto que ellos quieren siempre la paz. (AVp1,2b)

(73) Cuando se hará menester de enṿiar un delegado reliĝiośo a un lugar sea en Constantinopla como en la provincia, se escoǵerá a torno de rolo ${ }^{35}$ uno de estos 17 ḥajamim ['rabinos'] por esta misión. (EOa,14)

(74) Todo ajeno, sin distincción de reliǵión, que él sea o non sotometido ['sometido'] a una protección ajena, puede oḅtener la naturaliźación a las condiciones siguientes: [...]. (BERc,29)

\subsection{Condicionales concesivas universales}

El tercer tipo de condicionales concesivas son las concesivo-condicionales universales ( $c f$. HASPELMATH y KöNIG 1998: 604-619). Muestran una gran variedad formal, pero comparten lo siguiente: «su significado abarca todas las situaciones posibles que se consideran relevantes, de forma que ninguna de ellas invalida la conclusión que la apódosis establece» (NGLE 2010: 3623). Para el español, se pueden destacar cuatro mecanismos que

${ }^{35}$ A torno de rolo: calco del francés à tour de rôle 'por turnos'. 
permiten expresar concesivo-condicionales universales: primero, estructuras formadas a partir de un pronombre relativo o interrogativo de carácter indefinido o generalizador y una forma del modo subjuntivo del verbo querer, en combinación con un verbo en subjuntivo en la cláusula subordinada: quien(es)quiera, cual(es)quiera, dondequiera, adondequiera, comoquiera, cuandoquiera y cuanto quiera ( $c f$. FlamenCO GARCía 1999: 3848-3849; NGLE 2010: 1627 y ss.); segundo, fórmulas con subjuntivo reduplicado y pronombre relativo intercalado (p. ej.: «vaya adonde vaya», «digan lo que digan», «sea como sea») ( $c f$. FlamenCo García 1999: 38483849; NGLE 2010: 3623); tercero, estructuras que expresan indistinción del tipo no matter, no importa; y cuarto, la estructura por + adjetivo + que + subjuntivo (p. ej.: «Por mucho que lo intentes, no tendrás éxito») ( $c f$. Flamenco García 1999: 3836-3838; Haspelmath y KöNig 1998: 619).

En las concesivo-condicionales universales en judeoespañol (84 ocurrencias) encontramos los mismos procedimientos. El recurso mayoritario (63 ocurrencias) es el empleo de pronombres relativos o interrogativos, combinados o no con el verbo querer y casi siempre acompañados por verbos en subjuntivo:

(75) Anoche vós tuviteš dicho que me conoceríaš si me víaš en cualquer lugar que fuese y bajo del vestido que fuese; y portanto yo estaba ahí enfrente de vós y vós me estuviteš mirando mientres munchas horas. $(\mathrm{BGn} 8,13)$

(76) Todo accionario, cual quiere sea su reśidencia, es considerado como tuviendo su domicilio legal en la civdad ande la soĉetá tiene su sedio ['sede']. (PALa,9)

(77) [Ester] - ¡Te puedes quejar cuanto quieres! Yo no puedo haćer nada. (GUEt5,19b)

(78) Este artícolo dećía: "Todos los súditos búlgaros, cuala que sea sus reliǵión, goźarán de una complida igualidad de diritos ['derechos']. [...]" (BERc,20)

(79) - ¿Cuála es esta proba? Cualunque ella sea yo la pasaré. (JJn6,11)

(80) Quien que seáš, vós no traičiréš esta confienza de un estrañero soto ['bajo'] vuestro techo. (SEDn,7) 
(81) Los documentos que se haćían entre jidiós non eran reconocidos si non eran escritos en almán o una de las otras lenguas. Por endelantre toda escritura, en qué lengua que sea, será reconocida. (AVp2,4b)

Segundo, aparecen construcciones concesivo-condicionales universales introducidas por la preposición por, en combinación con una expresión cuantitativa y, a excepción de un caso, con formas verbales del subjuntivo (14 ocurrencias):

(82) Yo mostraré cuánto vales. Y vamos a ver si el nombre que tú llevas, por tan grande que sea, bastará a encubrir tu baǰeźa y tu caracter malo. (FABt,380a)

Tercero, el corpus MemTet contiene seis ocurrencias con formas reduplicadas del verbo ser en presente o imperfecto de subjuntivo, con elementos relativos intercalados:

(83) Fortuné.- Esto es contra el uśo de la vida. J́ośef.-Sea lo que sea, yo no quero espośar ['casarme’]. (TSt14,4c)

Por último, aparece un caso que explicita el carácter universalizador mediante una forma negada del verbo importar:

(84) Ella no viste que las más modernas tualetas ['ropa'], último modelo de París o de Viena, su caśa y su morada contienen las más modernas mobilias ['mobiliario'], aquello que a ella le parece lo más elegante, no importa de cuál estil que sea. (MUJc,23)

Sintetizando, quisiéramos subrayar un rasgo mediante el que las concesivo-condicionales halladas en los textos sefardíes destacan frente a las demás categorías oracionales analizadas: la importancia del modo subjuntivo. Mientras que en las escalares el porcentaje de oraciones con formas verbales del subjuntivo en la prótasis apenas constituye el 10\%, en las alternativas y universales el subjuntivo es el recurso predilecto. Si además recordamos la casi ausencia de dicho modo en las oraciones condicionales, deducimos que en judeoespañol el subjuntivo constituye un procedimiento sintáctico decisivo para reflejar el creciente grado de abstracción de las oraciones: las condicionales expresan una única condición en la prótasis; las concesivo-condicionales escalares focalizan una -también única- condición, presentándola como la más extrema o inesperada de una hipotética escala de condiciones; las alternativas señalan 
dos condiciones opuestas; y las universales aluden a todo un conjunto de posibles hipótesis, razón por la cual su fuerza condicionante pierde influencia y resulta irrelevante.

\section{CONCLUSIONES}

La época estudiada (últimas décadas del siglo XIX y primeras del siglo $\mathrm{XX}$ ) es una época crucial para la historia de los judíos sefardíes y del judeoespañol. Como consecuencia de transformaciones profundas en todos los ámbitos de la vida, también fue necesario renovar y ampliar la lengua. Hasta la actualidad esta elaboración lingüística casi únicamente se ha estudiado en el nivel del léxico, pese a que los mismos procesos se pueden observar en la sintaxis, tal como lo demuestra el presente estudio.

Partiendo de las oraciones condicionales y concesivas en judeoespañol moderno escrito, hemos podido observar transformaciones entre épocas más antiguas y la época moderna (recuérdense la difusión del condicional en las apódosis condicionales, la introducción del conector concesivo malgrado [que] y la paulatina sustitución del hebraísmo afilú por las construcciones calcadas del francés con el elemento miśmo) y hemos encontrado elementos lingüísticos conservadores (p. ej. las ocurrencias ocasionales del futuro de subjuntivo) al lado de formas innovadoras (p. ej. el uso modal del imperfecto de indicativo en las oraciones condicionales). Algunas de las características y evoluciones analizadas coinciden con el español estándar, otras son diferentes, y mientras que en parte sirven para ampliar y modernizar la lengua (p. ej. el neologismo malgrado [que] y las estructuras galas con miśmo), a veces responden a la tendencia del judeoespañol de regularizar y simplificar la lengua (recuérdense el uso del modo indicativo en vez del subjuntivo, la conservación del futuro en las prótasis condicionales o la predilección por esquemas verbales simétricos).

Por lo que respecta a la influencia de las lenguas de contacto, hemos observado que la siempre destacada influencia francesa e italiana en la época moderna no se limita al léxico. En cambio, en todas las clases oracionales estudiadas hemos encontrado influencias de dichas lenguas, ante todo en los conectores y locuciones, pero en menor medida también en 
los usos modo-temporales de los verbos, además de en la fonética y en la semántica.

Todo lo dicho es prueba de que la modernización lingüística de los siglos XIX y XX no solo consistió en la integración de préstamos léxicos, sino que influyó en todos los niveles de la lengua sefardí. De hecho, especialmente las innovaciones sintáctico-formales son representativas para esta etapa de elaboración lingüística, puesto que esta última incluyó, al lado de la difusión de nuevos géneros textuales y una ampliación temática, una profunda diversificación estilística y discursiva. Por eso también afectó a ámbitos tan específicos como las clases oracionales aquí analizadas, las cuales, viceversa, se convierten en objetos de estudio idóneos para analizar e interpretar pormenorizadamente las transformaciones descritas. 
Bibliografía citada

Alarcos Llorach, Emilio (2002): Gramática de la lengua española (8ª reimpr. Madrid: Espasa Calpe).

Algeo, James E. (1972-1973): «The Concessive Conjunction in Medieval Spanish and Portuguese; its Function and Development», Romance Philology 26:1, 532-545.

BARNAÏ, Jacob (1992a): «Los sefardíes en el Imperio Otomano (siglos XV-XIX)», en María Antonia Bel Bravo (coord.), Diáspora sefardí (Madrid: Mapfre), 93-151.

BARNAÏ, Jacob (1992b): «La comunidad judía de Salónica (1430-1943)», en María Antonia Bel Bravo (coord.), Diáspora sefardí (Madrid: Mapfre), 153165.

Bartol Hernández, José Antonio (1986): Oraciones consecutivas y concesivas en las Siete Partidas (Salamanca: Universidad de Salamanca).

Benbassa, Esther y Aron Rodrigue (2004): Historia de los judios sefardíes. De Toledo a Salónica (Madrid: Abada Editores).

Berenguer Amador, Ángel (2002): «Rasgos sintácticos y morfológicos del verbo en dos obras de la lengua clásica sefardí», en Elena Romero (ed.), Judaísmo Hispano. Estudios en memoria de José Luis Lacave Riaño (2 vols. Madrid: CSIC), vol. I, 311-318.

Berenguer Amador, Ángel (2012): «La sintaxis del subjuntivo en judeoespañol», eHumanista 20, 47-62.

Birnbaum, Salomo (2011): Praktische Grammatik der Jiddischen Sprache (München: LINCOM; $1^{\text {a }}$ ed. 1917, Wien: A. Hartleben's Verlag).

Britannica = Encyclopaedia Britannica Online Academic Edition (2013) (Chicago: Encyclopædia Britannica, Inc.), en http://www.britannica.com (última fecha de consulta: 4 de diciembre de 2014).

BunisLex = Bunis, David M. (1993): A Lexicon of the Hebrew and Aramaic Elements in Modern Judezmo (Jerusalem: Magnes Press / Hebrew University).

BÜRKI, Yvette (2003): «Salónica en los umbrales del siglo XX», en Beatrice $\mathrm{SCH}_{-}$ MID (dir.), "Sala de pasatiempo": Textos judeoespañoles de Salónica impresos entre 1896 y 1916 (Basel: Romanisches Seminar der Universität Basel; ARBA 14), 17-20. 
BÜRKI, Yvette (2006): «El discurso periodístico de la prensa judeoespañola del siglo XIX», en Yvette Bürki, Beatrice Schmid y Armin Schwegler (eds.), Una lengua en la diáspora: el judeoespañol de Oriente (RILI IV:2), 53-76.

BÜRKI, Yvette (2012): El discurso periodístico en judeoespañol. El Avenir y La Época de Salónica (1901-1902) (Basel: Universität Basel. Tesis de habilitación inédita).

Camús Bergareche, Bruno (1990): «El futuro de subjuntivo en español», en Ignacio BosQue (ed.), Indicativo y subjuntivo (Madrid: Altea / Taurus / Alfaguara), 410-427.

Cano Aguilar, Rafael (2011): «Entre sintaxis histórica y el análisis del discurso: las condicionales en la historia del español (Edad Media y Siglos de Oro)», en Elena Carmona Yanes y Santiago Del Rey Quesada (coords.), Id est, loquendi peritia. Aportaciones a la Lingüística Diacrónica de los Jóvenes Investigadores de Historiografía e Historia de la Lengua Española (Sevilla: Universidad de Sevilla, Facultad de Filología, Departamento de Lengua Española, Lingüística y Teoría de la Literatura), 29-54.

Contreras, Lidia (1963): «Las oraciones condicionales», Boletín de Filología 15, 33-109.

Cortés Parazuelos, María Helena (1992): La expresión de la concesividad en español (Madrid: Universidad Complutense de Madrid. Tesis doctoral), en http://eprints.ucm.es/4314/1/AH3017401.pdf (última fecha de consulta: 4 de diciembre de 2014).

De Benmergui, Alicia V. (2007): «Historia de la familia Camondo», Milim Cultural, en http://www.milimcultural.com.ar/articulos/camondo.htm (última fecha de consulta: 4 de diciembre de 2014).

Deza EnRíquez, Ana-Jimena (1993): «Significación, aspectos y valores de las oraciones condicionales», Epos: Revista de Filología 9, 169-193, en http://e-spacio.uned.es/fez/eserv.php?pid=bibliuned:Epos-F4F3214CBCF7-D4C7-3680-9DEF3004B648\&dsID=Documento.pdf (última fecha de consulta: 4 de diciembre de 2014).

Di Meola, Claudio (1998): «Zur Definition einer logisch-semantischen Kategorie: Konzessivität als 'versteckte Kausalität'», Linguistische Berichte 175, 329-352.

Díaz Padilla, Fausto (1999): Gramática analítico descriptiva de la lengua italiana (Oviedo: Universidad de Oviedo, Servicio de Publicaciones). 
DíAz-Mas, Paloma (2000): «Pasado, presente ¿y futuro? de la literatura sefardí», Insula 647, 3-4, en http://insula.es/sites/default/files/articulos_muestra/ INSULA\%20647.htm (última fecha de consulta: 4 de diciembre de 2014).

DíAz-Mas, Paloma (2006): Los Sefardies: historia, lengua y cultura (4 ed., revisada. Barcelona: Riopiedras).

DLM = Alcaraz Varó, Enrique y María Antonia Martínez Linares (2004): Diccionario de lingüística moderna ( $2^{\mathrm{a}}$ ed., ampliada y actualizada. Barcelona: Ariel).

EBERENZ, Rolf (1990): «Sea como fuere. En torno a la historia del futuro de subjuntivo español», en Ignacio BosQue (ed.), Indicativo y subjuntivo (Madrid: Altea / Taurus / Alfaguara), 383-409.

EJ = Berenbaum, Michael y Fred Skolnik (eds.) (2007): Encyclopaedia Judaica ( $2^{\text {a }}$ ed. 22 vols. Detroit: Macmillan Reference USA).

Esbozo $(1973)$ = REAL ACADEMIA EsPAÑOLA (1973): Esbozo de una nueva gramática de la lengua española (Madrid: Espasa Calpe).

FAROQHi, Suraiya (2003): Kultur und Alltag im Osmanischen Reich. Vom Mittelalter bis zum Anfang des 20. Jahrhunderts ( $2^{\mathrm{a}}$ ed. München: C. H. Beck).

Flamenco García, Luis (1999): «Las construcciones concesivas y adversativas», en Ignacio Bosque y Violeta Demonte (dirs.), Gramática descriptiva de la lengua española. Vol. III: Entre la oración y el discurso. Morfología (Madrid: Espasa Calpe), 3805-3878.

García Moreno, Aitor (2004): Relatos del pueblo ladinán (Me`am Lo`eź de Éxodo) (Madrid: CSIC).

García Moreno, Aitor (2006): «Innovación y arcaísmo en la morfosintaxis del judeoespañol clásico», en Yvette Bürki, Beatrice SchMID y Armin SchwEGLER (eds.), Una lengua en la diáspora: el judeoespañol de Oriente (RILI IV:2), 35-51.

GarzantiDiz = РАтотA, Giuseppe (dir.) (2008): Garzanti Italiano. I grandi dizionari (ed. actualizada. Milano: Garzanti Linguistica).

GiLI Gaya, Samuel (1985): Curso superior de sintaxis española (15 $\mathrm{a}$ ed., reimpr. Barcelona: Biblograf).

Grevisse, Maurice (1980): Le bon usage. Grammaire française avec des remarques sur la langue française d'aujourd'hui (11 a ed. Paris-Gembloux: Duculot). 
Harris, Martin B. (1988): «Concessive Clauses in English and Romance», en John Haiman y Sandra A. Thompson (eds.), Clause Combining in Grammar and Discourse (Amsterdam / Philadelphia: John Benjamins Publishing Company), 71-99.

Harris, Tracy K. (1994): Death of a Language. The History of Judeo-Spanish (Newark / London / Toronto: University of Delaware Press / Associated University Presses).

Haspelmath, Martin y Ekkehard KöNIG (1998): «Concessive Conditionals in the Languages of Europe», en Johan VAN DER Auwera y Dónall P. Ó BaOILL (eds.), Adverbial Constructions in the Languages of Europe (Berlin / New York: Mouton de Gruyter), 563-640.

Hassán, Iacob M. (1995): «El español sefardí (judeoespañol, ladino)», en Manuel SEco y Gregorio SALVAdor (coords.), La lengua española, hoy (Madrid: Fundación Juan March), 117-140.

Hermodsson, Lars (1978): Semantische Strukturen der Satzgefüge im kausalen und konditionalen Bereich (Uppsala: Almqvist \& Wiksell).

Hernando CuAdrado, Luis Alberto (1998): «Sobre la expresión de la concesividad en español», Revista de Filología Románica 15, 123-133.

Herrero Ruiz de Loizaga, F. Javier (2005): Sintaxis histórica de la oración compuesta en español (Madrid: Gredos).

Hetzer, Armin (2001): Sephardisch. Judeo-español, Djudezmo. Einführung in die Umgangssprache der südosteuropäischen Juden (Wiesbaden: Harrassowitz).

IввA, Daniela (2010): «Los recursos lingüísticos que expresan concesividad», Interlingüística 20, en http://filcat.uab.cat/clt/XXIVAJL/Interlinguistica/ Encuentro\%20XXIV/Ibba_REVF.pdf (última fecha de consulta: 4 de diciembre de 2014).

$\mathrm{JE}=$ Jewish Encyclopedia. The Unedited Full-Text of the 1906 Jewish Encylopedia (2002-2011) (The Kopelman Foundation), en http://www.jewishencyclopedia.com (última fecha de consulta: 4 de diciembre de 2014).

Julián Mariscal, Olga (2007): «Las pseudocondicionales. Intento de clasificación», Interlingüística 17, 570-579, en http://dialnet.unirioja.es/servlet/ articulo?codigo=2317450 (última fecha de consulta: 4 de diciembre de 2014). 
KerEM, Yitzchak (1999): «The Europeanization of the Sephardic Community of Salonika», en Yedida K. Stillman y Norman A. Stillman (eds.), From Iberia to Diaspora. Studies on Sephardic History and Culture (Leiden / Boston / Köln: Brill), 58-74.

KLARE, Johannes (1958): Entstehung und Entwicklung der konzessiven Konjunktionen im Französischen (Berlin: Akademie-Verlag).

KöNIG, Ekkehard (1985): «Where Do Concessives Come From? On the Development of Concessive Connectives», en Jacek Fisiak (ed.), Historical Semantics. Historical Word-Formation (Berlin / New York / Amsterdam: Mouton Publishers), 263-282.

KöNIG, Ekkehard (1988): «Concessive Connectives and Concessive Sentences: Cross-Linguistic Regularities and Pragmatic Principles», en John A. HawKINS (ed.), Explaining Language Universals (Oxford / Cambridge: Basil Blackwell), 145-166.

KöNIG, Ekkehard (1991): «Konzessive Konjunktionen», en Armin Von Stechow y Dieter Wunderlich (eds.), Semantik. Semantics. Ein internationales Handbuch der zeitgenössischen Forschung. An International Handbook of Contemporary Research (Berlin / New York: Walter de Gruyter), 631-639.

KöNIG, Ekkehard y Peter EISENBERG (1984): «Zur Pragmatik von Konzessivsätzen», en Gerhard Stickel (ed.), Pragmatik in der Grammatik (Düsseldorf: Pädagogischer Verlag Schwann-Bagel), 313-332.

KÖNIG, Ekkehard y Johan VAN DER Auwera (1988): «Clause Integration in German and Dutch Conditionals, Concessive Conditionals, and Concessives», en John Haiman y Sandra A. Thompson (eds.), Clause Combining in Grammar and Discourse (Amsterdam / Philadelphia: John Benjamins Publishing Company), 101-133.

Levy, Avigdor (1992): The Sephardim in the Ottoman Empire (Princeton / New Jersey: The Darwin Press).

LindSCHOUw, Jan (2011): Étude des modes dans le système concessif en français du $16^{e}$ au $20^{e}$ siècle et en espagnol moderne. Évolution, assertion et grammaticalisation (København: Museum Tusculanum Press / Université de Copenhague).

LuQueT, Gilles (1988): «Sobre la desaparición del futuro de subjuntivo en la lengua hablada de principios del siglo XVI», en Manuel ArIZA, Antonio SalvaDOR y Antonio Viudas (eds.), Actas del I Congreso Internacional de Historia 
de la Lengua Española (Cáceres, 30 de marzo-4 de abril de 1987) (2 vols. Madrid: Arco Libros), vol. I, 509-514.

Marcos Marín, Francisco (1972): Aproximación a la gramática española (Madrid: Cincel).

Marcos Marín, Francisco, F. Javier Satorre Grau y M. ${ }^{a}$ Luisa Viejo Sánchez (2002): Gramática española (2a ed. Madrid: Síntesis).

Martín Heredia, María (1990): El teatro sefardí: Edición de textos y estudio de la morfología derivativa nominal (2 vols. Madrid: Universidad Autónoma de Madrid. Tesis doctoral).

Martínez Moreno, Annette (1998): «Konzessive Konnektiva in der Geschichte des Französischen», en Udo L. Figge, Franz-Josef Klein y Annette MartíNEZ Moreno (eds.), Grammatische Strukturen und grammatischer Wandel im Französischen. Festschrift für Klaus Hunnius zum 65. Geburtstag (Bonn: Romanistischer Verlag), 383-406.

Mazzoleni, Marco (1996): «I costrutti concessivi», Studi italiani di linguistica teorica e applicata 25:1, 47-65.

MinerVInI, Laura (2002): «La formación de la koiné judeo-española en el siglo XVI», Revue de Linguistique Romane 66:263-264, 497-512.

MinERVInI, Laura (2008): «Formación de la lengua sefardí», en Iacob M. Hassán, Ricardo Izquierdo Benito (coords.) y Elena Romero (ed.), Sefardíes: Literatura y lengua de una nación dispersa (Cuenca: Universidad de Castilla-La Mancha), 25-49.

Montero Cartelle, Emilio (1992): «Tendencias en la expresión de la concesividad en el castellano medieval», en Verba. Anuario Galego de Filoloxía 19 (Santiago de Compostela: Universidade de Santiago de Compostela), 107-128.

Montolío, Estrella (1999a): «Las construcciones condicionales», en Ignacio Bosque y Violeta Demonte (dirs.), Gramática descriptiva de la lengua española. Vol. III: Entre la oración y el discurso. Morfología (Madrid: Espasa Calpe), 3643-3737.

Montolío, Estrella (1999b): «jSi nunca he dicho que estuviera enamorada de él! Sobre construcciones independientes introducidas por si con valor replicativo», Oralia 2, 37-69.

Montoliu, César y Johan Van Der Auwera (2004): «On Judeo-Spanish Conditionals», en Olga Mišeska Tomić y Aida Martinovic-Zic (eds.), Balkan Syn- 
tax and Semantics (Amsterdam / Philadelphia: John Benjamins Publishing Company / John Benjamins North America), 461-474.

Moral Del Hoyo, María del Carmen (2012): «La condicionalidad en documentos notariales medievales castellano-norteños (1200-1330)», en Sara GómEZ SeIbANe y Carsten SinNer (eds.), Estudios sobre tiempo y espacio en el español norteño (San Millán de la Cogolla: Cilengua), 197-227.

NARBONA JimÉNEZ, Antonio (1990): Las subordinadas adverbiales impropias en español (II) (Causales y finales, comparativas y consecutivas, condicionales y concesivas). (Málaga: Librería Ágora).

NehamaDict = Nehama, Joseph (1977): Dictionnaire du judéo-espagnol. Avec la collaboration de Jesús CANTERA (Madrid: CSIC).

NGLE (2010) = REAL ACADEMIA ESPAÑOLA (2010): Nueva gramática de la lengua española ( $2^{\mathrm{a}}$ tirada, corregida. 2 vols. Madrid: Espasa Libros).

NRedhouse = Redhouse Yeni Türkçe - Ingilizce Sözlük / New Redhouse Turkish - English Dictionary (1968) (İstanbul: Redhouse Press).

PASch, Renate (1994): Konzessivität von wenn-Konstruktionen (Tübingen: Gunter Narr).

Penny, Ralph (2006): Gramática histórica del español (2ª ed. Barcelona: Ariel).

Polo, José (1971): Las oraciones condicionales en español (Ensayo de teoría gramatical) (Granada: Universidad de Granada/CSIC).

Porcar Miralles, Margarita (1993): La oración condicional. La evolución de los esquemas verbales condicionales desde el latín al español actual (Castelló: Universitat Jaume I).

RiEder-ZelenKo, Elena (2014): «El léxico relacionado con la vida urbana en $L a$ Buena Esperanza», en Yvette BÜRKI y Elena RoMERo (eds.), La lengua sefardí. Aspectos lingüísticos, literarios y culturales (Berlin: Frank \& Timme), 135-150.

Rivarola, José Luis (1976): Las conjunciones concesivas en español medieval y clásico. Contribución a la sintaxis histórica española (Tübingen: Niemeyer).

RIvas, Elena (1989): «Observaciones sobre las concesivas. Su comparación con las condicionales y las adversativas», en Verba. Anuario Galego de Filoloxía 16, 237-255. 
RIVAs, Elena (1990): «A propósito de condicionales y concesivas reales. Referencias diacrónicas en torno a estas últimas», en Verba. Anuario Galego de Filoloxía 17, 159-169.

Rodrigue, Aron (1990): French Jews, Turkish Jews. The Alliance Israélite Universelle and the Politics of Jewish Schooling in Turkey, 1860-1925 (Bloomington / Indianapolis: Indiana University Press).

Rodríguez Rosique, Susana (2008): Pragmática y Gramática. Condicionales concesivas en español (Frankfurt am Main: Peter Lang).

Rofes Moliner, Xavier (2012): «Les construccions concessives en el Curial $e$ Güelfa», en Antoni Ferrando FrancÉs (ed.), Estudis lingüístics i culturals sobre Curial e Güelfa. Novell·la cavalleresca anònima del segle XV en llengua catalana (2 vols. Amsterdam / Philadelphia: John Benjamins Publishing Company / John Benjamins North America), vol. II, 743-794.

Rojo, Guillermo y Emilio Montero Cartelle (1983): La evolución de los esquemas condicionales (Potenciales e irreales desde el poema del Cid hasta 1400) (Santiago de Compostela: Universidade de Santiago de Compostela[= Verba. Anuario Galego de Filoloxía, Anexo 22]).

Romero Castelló, Elena y Uriel Macías Kapón (1994): Los judios de Europa. Un legado de 2000 años (Madrid: Anaya).

ROMERO, Elena (1992): La creación literaria en lengua sefardí(Madrid: Mapfre).

Romero, Elena (2008): «Historia y literatura», en Iacob M. HAssán, Ricardo IzQUIERdo Benito (coords.) y Elena Romero (ed.), Sefardies: Literatura y lengua de una nación dispersa (Cuenca: Universidad de Castilla-La Mancha), 155-192.

SAla, Marius (1983): «Sobre el verbo del judeoespañol», Romanica Gandensia 20, 73-80.

SÁNCHEZ LÓPEZ, Cristina (1995): "Construcciones concesivas con para», Revista Española de Lingüística 25:1, 99-123.

SÁnchez, Rosa (2008): “¡TTú ya sabes hablar la habla que hablan los “civiliźados”!’ - La lengua como marca de cambio generacional en El Angustiador», en Hilary Pomeroy, Christopher J. Pountain y Elena Romero (eds.), Proceedings of the Fourteenth British Conference on Judeo-Spanish Studies (26-28 June 2006) (London: Queen Mary, University of London), 203-211. 
SÁNCHEZ, Rosa (2012): «Consideraciones para la forja de un registro metateatral judeoespañol», en Yvette Bürki, Manuela Cimeli y Rosa SÁNCHEZ (coords.), Lengua, Llengua, Llingua, Lingua, Langue. Encuentros filológicos (ibero) románicos. Estudios en homenaje a la profesora Beatrice Schmid (München: Peniope), 390-407.

Santana Marrero, Juana (2003): Las oraciones condicionales: estudio en la lengua hablada (Sevilla: Publicaciones de la Universidad de Sevilla).

SchlumpF, Sandra (2012a): “"Qué bueno era si tenía yo trenta mil francos!”. El uso de los tiempos verbales en las oraciones condicionales en judeoespañol moderno», en Yvette BüRKI y Carsten SinNER (eds.), Tiempo y espacio y relaciones espacio-temporales en judeoespañol (München: Peniope), 35-50.

SchlumpF, Sandra (2012b): «Notas sobre las oraciones pseudocondicionales en judeoespañol moderno», en Yvette Bürki, Manuela Cimeli y Rosa SÁNCHEZ (coords.), Lengua, Llengua, Llingua, Lingua, Langue. Encuentros filológicos (ibero)románicos. Estudios en homenaje a la profesora Beatrice Schmid (München: Peniope), 408-419.

SchlumPF, Sandra (2014): «Las oraciones condicionales concesivas y sus formas de expresión en judeoespañol moderno», en Yvette BüRKI y Elena RoMERO (eds.), La lengua sefardí. Estudios lingüísticos, literarios y culturales (Berlin: Frank \& Timme), 209-233.

Schmid, Beatrice (2006a): Ladino (Judenspanisch) - eine Diasporasprache (Bern: Schweizerische Akademie der Geistes- und Sozialwissenschaften).

Schmid, Beatrice (2006b): «La transcripción de datos judeoespañoles de fuentes aljamiadas», en Yvette Bürki y Elwys De Stefani (eds.), Trascrivere la lingua. Dalla filologia all'analisi conversazionale / Transcribir la lengua. De la Filología al Análisis Conversacional (Bern: Peter Lang), 63-83.

Schmid, Beatrice (2008): «La lengua sefardí en su plenitud», en Iacob M. HASSÁN, Ricardo IzQUIERdo BENITO (coords.) y Elena Romero (ed.), Sefardíes: Literatura y lengua de una nación dispersa (Cuenca: Universidad de CastillaLa Mancha), 51-79.

Schmid, Beatrice (2010): «'Por el adelantamiento de la nación'. Las ideas lingüísticas de Abraham A. Cappon», en Paloma DíAz-Mas y María SÁNchez PÉrEz (eds.), Los sefardíes ante los retos del mundo contemporáneo. Identidad y mentalidades (Madrid: CSIC), 99-112. 
SCHNEIDER, Susanne (1995): Der Ausdruck der Konditionalität im Französischen und Spanischen. Eine sprachvergleichende Untersuchung der Verwendung der Verbformen in Protasis und Apodosis des Si-Satzes (Frankfurt am Main: Peter Lang).

SECO, Rafael (1988): Manual de gramática española. Revisado y ampliado por Manuel SECo (11 ${ }^{\mathrm{a}}$ ed. Madrid: Aguilar).

SERRANO, María José (1994): La variación sintáctica: formas verbales del periodo hipotético en español (Madrid: Entinema).

SöHRMAN, Ingmar (1991): Las construcciones condicionales en castellano contemporáneo (Uppsala: University of Uppsala).

SteuerwaldWb = STEueRwald, Karl (1988): Türkisch-Deutsches Wörterbuch. Türkçe-Almanca Sözlük (2 $2^{\mathrm{a}}$ ed., mejorada y ampliada. Wiesbaden: Otto Harrassowitz).

SubaK, Julius (1905): «Das Verbum im Judenspanischen», en Bausteine zur Romanischen Philologie, Festgabe für A. Mussafia (Feb. 1905) (Halle a. d. S.: Max Niemeyer), 321-331.

Subak, Julius (1906): «Zum Judenspanischen», Zeitschrift für Romanische Philologie 30, 129-185.

VAlentín del BARrio, M. ${ }^{a}$ del Carmen (2006): «Las formas verbales en un corpus de trece coplas sefardíes», en José Jesús De Bustos Tovar y José Luis Girón Alconchel (eds.), Actas del VI Congreso Internacional de Historia de la Lengua Española (Madrid, 29 de septiembre-3 de octubre de 2003) (3 vols. Madrid: Arco Libros), vol. III, 2585-2597.

VAllejo, César (1922): «Notas sobre la expresión concesiva», Revista de Filología Española 9:1, 40-51.

VArol, Marie-Christine (2004): Manuel de judéo-espagnol: Langue et culture (nueva ed., revisada y ampliada. Paris: Langues \& Mondes / L'Asiathèque).

Veiga, Alexandre y Manuel Mosteiro Louzao (2006): El modo verbal en cláusulas condicionales, causales, consecutivas, concesivas, finales y adverbiales de lugar, tiempo y modo (Salamanca: Universidad de Salamanca).

Veinstein, Gilles (1993): «El Imperio Otomano, desde 1492 hasta finales del siglo XIX», en Henry Méchoulan (dir.), Los judios de España. Historia de una diáspora, 1492-1992 (Madrid: Trotta), 347-372. 
WAHL, Jean-Jacques (dir.) (1997): «Dossier: Les Juifs de Salonique», Les Cahiers de l'Alliance Israélite Universelle 17, 26-36.

WANG, Fang (1996): Die konzessive Beziehung in der deutschen Gegenwartssprache. Untersuchung zu ihrer Syntax, Semantik und Pragmatik (Frankfurt am Main / Bern et al.: Peter Lang).

WeIKer, Walter F. (1992): Ottomans, Turks and the Jewish Polity. A History of the Jews of Turkey (Lanham / New York / London: University Press of America / The Jerusalem Center for Public Affairs).

ZingarelliVoc $=$ ZINGARELLI, Nicola (2010): Vocabolario della lingua italiana (12 ${ }^{\mathrm{a}}$ reimpr. Bologna: Zanichelli).

Recibido: $19 / 01 / 2015$

Aceptado: 06/07/2015 